\title{
Two-way commuting: Asymmetries from time use
}

\section{surveys*}

\author{
José Ignacio Giménez-Nadal, University of Zaragoza, BIFI (Spain) \\ José Alberto Molina, University of Zaragoza, IEDIS (Spain), IZA (Germany) \\ Jorge Velilla, University of La Rioja, IEDIS (Spain)
}

\begin{abstract}
Daily commuting of workers is a complex phenomenon that has long attracted research attention and, despite the significant literature acknowledging differences between morning and evening commuting, commuting trips to and from work are considered symmetric in much of the prior research. We explore the asymmetries in time spent commuting to and from work, in seven countries, using detailed time use records from the Multinational Time Use Study (MTUS). We focus on the duration, mode of transport, and timing of commuting trips, and we provide evidence of the socio-demographic characteristics related to such asymmetries. We find that commutes to work (usually in the morning) last longer than commutes from work (usually in the afternoon or evening), although there are quantitative differences among countries. The timing of commuting also differs across countries, although commutes to work are more concentrated at certain hours in the morning than commutes from work. Our results may provide a better analysis of public policies, and open questions for future research, tackling the correlation between commuting behaviors and worker well-being, land use and city structure, and extreme commuting, among others.
\end{abstract}

Keywords: Two-way commuting; commuting symmetries; time use survey; Multinational Time Use Study

\footnotetext{
${ }^{*}$ Correspondence to J.I. Giménez-Nadal. Department of Economic Analysis. C/ Gran Vía 2, 50005 Zaragoza, Spain. Email: ngimenez@unizar.es.

Acknowledgement: This paper has benefitted from funding from the Spanish Ministry of Science and Innovation (Project "PID2019:108348RA-I00"), and the Government of Aragón (Project "S32-20R").
} 


\section{Introduction}

The daily commuting of workers is a complex phenomenon that has long attracted research attention. In Europe, one of five workers commute more than 90 minutes per day, the average one-way commute in the United States increased to a new high of 27.6 minutes in 2019 (Burd, Burrows and McKenzie, 2021), and commuting times are increasing in many developed economies (Susilo and Maat, 2007; Kirby and LeSage, 2009; McKenzie and Rapino, 2009; Gimenez-Nadal, Molina and Velilla, 2018a). ${ }^{1}$ Furthermore, the negative consequences of commuting spread to the daily lives of individuals. For instance, longer commutes have been related to decreased worker health outcomes, lower subjective and psychological well-being, increased stress and sickness absenteeism, lower worker productivity, and significant negative effects on wages (Kahneman and Krueger, 2006; van Ommeren and Gutierrez-i-Puigarnau, 2011; Mulalic, van Ommeren and Pilegaard, 2014; Kunn-Nelen, 2016; Grinza and Rycx 2020). Moreover, commuting is related to the question of how economic activity affects the environment. In the United States, beginning in 2016, the transportation sector overtook the power sector as the primary source of GHG emissions (Bleviss, 2021). Transportation currently accounts for a quarter of the European Union's greenhouse gas emissions (European Commission, 2019).

Despite the importance of the topic, much prior research has not considered that commuting trips to and from work may be asymmetric in terms of duration, concentration around a certain hour of the day, and mode of transport. As a result, asymmetries in twoway commuting time are an under-investigated issue, with very few exceptions. ${ }^{2}$ Asymmetries in two-way commuting times are important to analyze, as considering commuting as a symmetrical phenomenon may limit the conclusions obtained in prior studies. For instance, Smith (2017) analyzes the commute to work and finds that traffic congestion significantly decreases commuter well-being. If the morning commute is concentrated at peak hours, in comparison to evening commuting, this leads to more traffic congestion in the mornings and thus lower well-being of workers, which may ultimately

\footnotetext{
1 https://www.sdworx.com/en/press/2018/2018-09-20-more-than-20percent-of-europeans-commute-at-least-90-minutesdaily

${ }^{2}$ The literature on road pricing mainly focuses on one part (the morning) of commuting trips, and the analysis of commuting from work is left out of the analysis. Recently, Coria and Zhang (2017) studied asymmetries in commuting, finding significant differences between morning and evening commuting.
} 
affect their productivity (Oswald, Proto and Sgroi, 2015). This phenomenon may justify firms and governments applying policies where their workers have flexibility in their starting times. Gimenez-Nadal and Molina (2019) show that longer commutes are related to more negative feelings during childcare activities, which may have detrimental effects on the education of children. However, as in most studies using time use surveys (GimenezNadal and Molina, 2016, Gimenez-Nadal, Molina and Velilla, 2018a, 2018b, 2020b) the time in commuting is computed as the total time in commuting during the day, without considering that the morning commute may be longer and thus more significant in terms of those negative feelings.

On theoretical grounds, the literature has defined "excess" commuting (Hamilton, 1982, 1989) and "extreme" commuting (Marion and Horner, 2007; Bai et al., 2020) as tools to analyze the optimal commuting behavior of workers. But no asymmetries in commuting travels are implicitly considered within this literature. In the case of excess commuting, if the morning commute is done at peak hours of the day, while the evening commute is subject to less traffic congestion, the definition of excess commuting will vary depending on the time of the day and the mode of transport used. In the case of "extreme" commuting, if asymmetries in commuting time are taken into account, the prior literature could redefine the definition of extreme commuting that is based on total commuting time (Jones et al., 2008, Vincent-Geslin and Ravalet, 2016) towards a definition that is based on the duration of specific journeys (Marion and Horner, 2007; Bai et al., 2020).

Within this framework, this paper explores whether the time spent commuting to and from work is symmetric, with a focus on the timing of these activities, the means of transport used, and the differences in duration of such trips. To the best of our knowledge, the asymmetry of commuting trips, for a group of countries, has not previously been analyzed. To that end, we explore the time spent commuting to and from work in Canada, Finland, France, South Korea, Spain, the UK, and the US, using detailed time use records from the Multinational Time Use Study (MTUS). We find that, in general, commutes to work last longer than commutes from work, for both women and men, but with quantitative differences among countries. The timing of commuting also differs across countries, but generally commutes to work are more concentrated at certain hours than commutes from work. Furthermore, there appear to be some differences in commuting to work, and commuting from work times, that are partially explained by worker characteristics. Finally, 
we find a significant connection between the differences in the commuting to/from work, and the mode of transport, although this correlation is not heterogeneous between countries. The use of public transport is related to longer times of commuting to work, and shorter times of commuting from work, in all the countries except France. However, commuting by private vehicle has mixed effects on commuting differences, which can largely be explained by variations in transport infrastructures.

The remainder of the paper is structured as follows. Section 2 presents a literature review on commuting and its correlations with individual, urban, and environmental attributes. Section 3 presents the data and describes the main variables of interest. Section 4 describes the timing of commuting to and from work (when, specifically, do workers commute). Section 5 shows descriptive evidence on the time devoted to commuting, together with the modes of transport used. Section 6 empirically analyzes the sociodemographic factors related to differences in the time spent commuting to and from work. Section 7 presents a discussion of the results, and Section 8 draws conclusions.

\section{Literature review}

\section{Commuting and worker characteristics}

An extensive literature has analyzed worker commuting behaviors, focusing on the relationship between commuting and the personal socioeconomic characteristics of workers. First, these studies have concluded that males' and females' commuting behaviors are different, as males spend more time commuting than do their female counterparts. ${ }^{3}$ Furthermore, gender differences in commuting behaviors have been linked to existing differences in housework times, other time allocations, and wages (Iwata and Tamada, 2014;

\footnotetext{
${ }^{3}$ Studies reporting the existence of a commuting gender gap include Kain (1962), Hanson and Johnston (1985), White (1986), Grieco, Pickup and Whipp (1989), Dex, Clark and Taylor (1995), Turner and Niemeirer (1997), Lee and McDonald (2003), Moss, Jack and Wallace (2004), Crane (2007), Mok (2007), Sandow (2008), van Ommeren and van der Straaten (2008), Sandow and Westin (2010), Roberts, Hodgson and Dolan (2011), Dargay and Clark (2012), McQuaid and Chen (2012), O'Kelly, Niedzielski and Gleeson (2012), Dickerson, Hole and Munford (2014), Gimenez-Nadal and Molina (2014, 2016), Oakil, Nijland and Dijst (2016), Gimenez-Nadal, Molina and Velilla (2018a, 2020a), Albert, Casado-Díaz and Simón (2019), Le Barbanchon, Rathelot and Roulet (2019), and Nafilyan (2019).
} 
Gimenez-Nadal, Molina and Velilla, 2018a), gender roles and identity values constraints (Sandow and Westin, 2010), and transportation needs (Gimenez-Nadal and Molina, 2016).

The level of education is also related to the commuting behavior of workers, as highly educated individuals who look for more specialized job positions seem to be willing to spend more time commuting (commute longer distances) to access these jobs (Rouwendal and Nijkamp, 2004; Dargay and van Ommeren, 2005; Sandow and Westin, 2010; Dargay and Clark, 2012). Age, race, and citizenship status are also related to commuting time (Aguiar and Hurst, 2007; van Ommeren and van der Straaten, 2008; Sevilla, Gimenez-Nadal and Gershuny, 2012; McQuaid and Chen, 2012; Gimenez-Nadal, Molina and Velilla, 2018a, 2018b; Albert, Casado-Díaz and Simón, 2019). Several authors have concluded that commuting and employment type are connected, as commutes change with worker occupation, and there are differences in commuting behaviors between employees and selfemployed workers, and between private sector employees and public workers (van Ommeren and van der Straaten, 2008; McQuaid, 2009; McQuaid and Chen, 2012; Walks, 2014; Gimenez-Nadal, Molina and Velilla, 2018a, 2020a; Albert, Casado-Díaz and Simón, 2019). Additionally, the number of hours usually worked per week by respondents is also important in determining commuting behavior, as some authors have found a positive link between work hours and commuting (Gutierrez-i-Puigarnau and van Ommeren, 2010).

Furthermore, household composition has been found to be a significant determinant of commuting behaviors (Hanson and Johnston, 1985; Johnston, 1992; Lee and McDonald, 2003; McQuaid and Chen, 2012; Gimenez-Nadal and Molina, 2016). For instance, married and unmarried respondents have been found to commute differently, with married workers commuting longer time/distance, relative to the commutes of single workers (Roberts, Hodgson and Dolan, 2011; McQuaid and Chen, 2012; Gimenez-Nadal, Molina and Velilla, 2018a). In this sense, some authors have analyzed the commuting behavior of members of couples and have reported that spouses' commuting behaviors are related (Carta and De Philippis 2018; Hong, Lee and McDonald 2018). The presence of children has also been linked to different commuting behaviors, especially among women (Hanson and Johnston, 1985; Lee and McDonald, 2003; McQuaid and Chen, 2012); according to the Household Responsibilities Hypothesis (Gimenez-Nadal and Molina, 2016), mothers spend more time in childcare activities and other unpaid work activities than do males and they need more time for childcare than female workers without kids, leading to shorter commutes. Beyond 
that, the availability of cars in the household is also linked to different commuting times (Dargay and Clark, 2012; McQuaid and Chen, 2012).

Some authors have studied how commuting time correlates to other worker activities and time-allocation decisions (see Chatterjee et al., 2020). In an urban efficiency wages context, commuting time is considered a shock to worker time endowments (Zenou, 2006, 2009). According to these models, longer commutes produce reduced worker productivity through their impact on leisure (Ross and Zenou, 2008). In this context, Gimenez-Nadal, Molina and Velilla (2018b, 2020b) show positive evidence for the US and European countries that longer commutes are associated with reduced leisure time, and compensated for with increased shirking behaviors at work (i.e., non-work activities at the workplace). In a different context, the correlation between commuting times and other daily activities has been analyzed, including analyses of leisure and childcare (Roberts, Hodgson and Dolan, 2011; Gimenez-Nadal, Molina and Velilla, 2019), personal care activities (Rosales-Salas and Jara-Díaz, 2017), and labor supply (Connolly, 2008, 2018; Gershenson, 2013; Jessoe, Manning and Taylor, 2018; Krüger and Neugart, 2018). The impacts on worker daily activities have been found to produce work-family imbalances (Christian, 2012; Hilbrecht, Smale and Mock, 2014).

Applied research has routinely focused on commuting as a solitary, individual process, disregarding the potential for sharing a commute with others. Roberts, Hodgson and Dolan (2011) analyze household commutes, but do not directly address whether commutes are done jointly. Picard, de Palma and Dantan (2014), and Chiappori et al. (2014) studied the joint commuting behaviors of French households in a collective setting (Chiappori, 1988, 1992), focusing on bargaining power and joint commuting decisions, while de Palma, Lindsey and Picard (2015) found that couples tend to coordinate their commuting behaviors. Picard, Dantan and de Palma (2018) conclude that car ownership is endogenously related to joint commuting behaviors in Paris, using a "value of time" model (see Train and McFadden, 1978), and de Palma, Inoa and Picard (2014) and Picard, Dantan and de Palma (2018) provide reviews of the scarce research on commuting as a joint activity.

\section{Commuting and geographical characteristics}


Prior literature has identified a complex relationship between the commuting behavior of workers, and urban forms and geographic characteristics (Cropper and Gordon, 1991; Small and Song, 1992; Manning, 2003; Rodriguez, 2004; Gimenez-Nadal, Molina and Velilla, 2018a). For instance, one theory that links worker commutes and urban forms is the "Monocentric city" model (Alonso, 1964; Mills, 1967; Muth, 1969), a descriptive model of cities with a central business district, to analyze the proximity of housing and workplaces. The "Polycentric city" model (Muller, 1981; Garreau, 1991; Knox and McCarthy, 2005), which considers multiple business districts, is another model that accounts for complex relationships between commuting and urban forms. Another theory that links commuting times and urban forms is the Spatial Mismatch Hypothesis (see a review in Gobillon, Selod and Zenou, 2007). According to this theory, there is a disconnection between inner city ghettos and the outskirts, and low-skilled workers reside in ghettos in the city center, while most of the low-skilled job vacancies are in the outskirts. Such disconnection causes poor labor market outcomes among low-skilled workers, relative to highly-skilled workers.

Empirically, several authors have analyzed the relationship between urban forms/geographic characteristics and workers' commuting behavior, although this relationship is complex, as commuting is correlated with different interactions of geographical and regional attributes, and also to stochastic or unobservable factors, such as weather conditions (Connolly, 2008, 2018; Jessoe, Manning and Taylor, 2018; Krüger and Neugart, 2018). Despite a lack of consensus about the particular channels through which the urban/metropolitan level may affect commuting times (Manning, 2003; Rodríguez, 2004; van Acker and Witlox, 2011; Gimenez- Nadal, Molina and Velilla, 2018a), there is some agreement about how certain urban characteristics relate to commuting behaviors. For instance, population size of the area of residence is positively correlated with worker commuting times (Gordon, Kumar and Richardson, 1989; Mieszkowski and Mills, 1993; Kahn, 2000). Moreover, workers living in lower-density regions, and workers living in large cities, have longer commutes, relative to workers living in middle-density regions (White, 1988; Hamilton, 1989; Gordon, Kumar and Richardson, 1989; Kahn, 2000; van Ommeren and van der Straaten, 2008).

Similarly, Gimenez-Nadal, Molina and Velilla (2018a, 2020a) found that, in the US and European countries, workers on the fringe of metropolitan areas and in large cities are those who commute longer. Conversely, Susilo and Maat (2007) found that, in the Netherlands, 
the influence of urban form on travel behavior is unique, depending on commuting model estimates. All in all, commuting has been identified as depending on metropolitan characteristics, in a context in which housing determines commuting behaviors in a significant way (Cutler and Gleaser, 1997; Ross and Zenou, 2008; Gutierrez-i-Puigarnau, Mulalic and van Ommeren, 2016). In this context, Gimenez-Nadal, Molina and Velilla (2019) identified the type of housing unit, the residential location within cities, and the population size of the area of residence as the most important factors when predicting commuting time in the US, using algorithmic techniques that account for model overfitting and predictive power. ${ }^{4}$

Naess (2003) analyzed the commuting and travel behavior of workers, and concluded that urban structural characteristics influence travel behaviors across city sizes, with the location of worker residence within the city being the most important factor. The distance from the outskirts to downtown areas, and population density, are also found to be relevant, which is in line with prior analyses studying city size and commuting behaviors. In a recent analysis, Naess et al. (2019) found that city structure not only affects worker commutes, but also non-travel trips. The effects include transport mode choices and commuting distance, and non-work trips are also related to the local environment and the neighborhood. The extent to which commuting time to work, or commuting time from work, are correlated similarly or differentially to these urban forms and geographical characteristics remains unclear. A review of commuting modes and how they depend on workplaces and urban forms is given in Naess, Tønnesen and Wolday (2019).

\section{Excess commuting and extreme commuting}

Two important streams in the literature of commuting are those of "excess" commuting and "extreme" commuting. The analysis of excess commuting, or wasteful commuting, was first proposed by Hamilton $(1982,1989)$. In these studies, the monocentric model (Alonso, 1964; Mills, 1967; Muth, 1969) was used to analyze whether worker commutes were optimal in urban areas, in terms of houses and job choices, resulting in a significant part of worker

\footnotetext{
${ }^{4}$ Commuting is also related to land use. Analyses on this topic include Manaugh, Miranda-Moreno and ElGeneidy (2010), van Acker and Witlox (2011), Burger et al. (2011), Hu and Schneider (2017), Ma et al. (2017), Guirao, Campa and Casado-Sanz (2018), Jin (2019), and Hu (2021). See Rouwendal and Nujkamp (2004), Naes (2006), and Gimenez-Nadal, Molina and Velilla (2020a) for reviews of the literature.
} 
commuting distances being wasteful. Then, excess commuting refers to the difference between actual commuting trips, and the optimal commuting, given the urban context conditional on workers optimizing spatial arrangements (Horner, 2002). More recently, several authors have analyzed excess commuting, and chronological reviews are provided by Ma and Banister (2006) and Kim and Horner (2021). For instance, Hamilton (1982) reported that about $90 \%$ of urban commutes were excess commuting in the US, while White (1988) found that only about $10 \%$ of commutes were wasteful. Horner (2002) formulates a model for excess commuting in the US in terms of the commuting capacity of a city (i.e., the difference between the theoretical maximum and minimum commutes), and how much of this capacity is consumed (i.e., the current levels of commuting). In a recent analysis, Kim and Horner (2021) study the impact of the recent 2007-2009 economic crisis (the socalled "Great Recession") on excess commuting in the US in terms of job-housing balance, finding that private sector workers were strongly affected by the Great Recession in terms of excess commutes impacting their commuting efficiency, although public sector workers' job-housing balance was also affected.

The literature on extreme commuting is limited, compared to the analyses of excess commuting (Bai et al., 2020, provide a recent review on the topic). These studies focus on extremely long commuting trips, in terms of either distance traveled or time spent in such trips. For instance, some authors consider that extreme commuters are those individuals who spend more than 60 minutes per day (Jones et al., 2008), or more than 100 minutes per day commuting (Vincent-Geslin and Ravalet, 2016); while others define extreme commutes as trips that last more than 90 minutes (Marion and Horner, 2007; Bai et al., 2020), or more than 45 minutes (Sandow, Westerlund and Lindgren, 2014). In terms of distance, extreme commutes have been identified as distances longer than $17 \mathrm{~km}$ (Maoh and Tang, 2012), or $20 \mathrm{~km}$ (Champion, Coombes and Brown, 2009). See Bai et al. (2020) for a discussion of the definitions of extreme commuting. All in all, extreme commutes have been found to be a constraint, instead of an efficient choice, and their study has been focused on particular commuting modes and regions (Marion and Horner, 2007).

\section{Commuting modes and environmental issues}


The analysis of commuting modes, and the study of sustainable or green commuting, has also been evident in recent years, since commuting has environmental consequences. Sustainable commuting modes include environmentally friendly travel modes, such as physical or active commuting (walking or cycling), the use of public transport (bus, tram, or subway), and carpooling, among others. ${ }^{5}$ Commuting by walking or cycling has been linked to income and housing expenditure, as higher income and more expensive housing are related to a decreased use of physical means of transport in the US (Plaut, 2005). Nevertheless, there seems to be no consensus, and results may depend on geographical location, as studies in New Zealand have found the opposite (McKim, 2014). In the same context, weather conditions (which depend on the geographical location) are also correlated with transport mode choices and, especially, with active commutes. Worker well-being is linked to transport modes, though the causal link remains unclear. On the one hand, increased physical activity by walking/cycling to work causes improvements in worker health outcomes and lower levels of stress. On the other hand, workers' health determines their ability to commute by physical means of transport. The existing research has provided mixed results for the causal link (Shephard, 2008; Bopp, Kaczynski and Besenyi, 2012; Humphreys, Goodman and Ogilvie, 2013; Martin, Goryakin and Suhrcke, 2014; Molina, Gimenez-Nadal and Velilla, 2020).

Other authors analyzing commuting modes in recent years include Wener et al. (2003), Dargay and Hanly (2007), Habib (2012), Shengxiao and Pegnjun (2015), Yang et al. (2015), Sun, Ermagun and Dan (2017), Tajalli and Hajbabaie (2017), Cavallaro and Dianin (2019), Gallo and Marinelly (2020), and Jacob et al. (2021). For instance, Wener et al. (2003) found that faster and more predictable commuting modes (i.e., newer public transport modes) reduce worker stress. Dargay and Hanly (2007) find that commuting mode choice is strongly affected by heterogeneity, and analyze the determinants of commuting by car in the UK. Habib (2012) develops a model of mode, start time, and duration, in Toronto, resulting in a useful empirical tool to study commuting mode choices. Shengxiao and Pegnjun (2015) study school commutes in China, finding that these are a complex phenomenon affected by population policy, education policy, and social groups. Yang et al. (2015) explore commuting modes in the US, with a focus on the relationship between transport mode and

\footnotetext{
${ }^{5}$ A recent review of sustainable commuting is provided by Molina, Gimenez-Nadal and Velilla (2020).
} 
distance traveled, concluding that commuting modes are related to environmental factors, policies, and work characteristics. Sun, Ermagun and Dan (2017) study commuting modes and the impact of the built environment in Shanghai, to conclude that policies aimed at reducing commuting distance also encourage physical commuting modes. Tajalli and Hajbabaie (2017) analyze the positive impact of active commuting on worker health in the US. Cavallaro and Dianin (2019) study challenges in mobility and public transport in Central European countries, with a focus on public transport services across borders. Cavallaro and Dianin (2019) find that the improvement of public transport modes in Central Europe has favored the labor integration of rural areas by increasing mobility. Finally, Jacob et al. (2021) analyze the correlation between commuting mode choices and worker health, using data from the UK. Recent reviews on commuting modes are shown in Gallo and Marinelli (2020) and Jacob et al. (2021).

Another determinant of commuting modes is urban form, as specific geographical characteristics, such as job density, population density, and housing prices may affect transport mode decisions. Specific city structure may favor trips by private vehicle, while others may be correlated with increased use of public transport, or to more workers commuting by physical means of transport (Cropper and Gordon, 1991; Manning, 2003; Deding, Filges and van Ommeren, 2009; Sandow and Westin, 2010).

The commuting mode is strongly connected with the environmental impact of daily commutes. Reducing private vehicle commuting by road pricing alleviates traffic congestion and pollution (Coria and Zhang, 2015, 2017; Long and Szeto, 2019; Vosough, Poorzahedy and Lindsey, 2020). In this context, it would be especially important to distinguish between commutes to work, concentrated in the morning, and commutes from work, concentrated in the evening, to study whether the emissions due to congestion are more or less significant, depending on the hour of the day. Some authors have accounted for differences between morning and evening commuting (Coria and Zhang, 2017), but in general terms commuting to and from work has been considered symmetric in these analyses, both in terms of distance travelled and time spent. Analyses of the environmental impact of commuting, and alternative transport modes to alleviate that impact include Plaut (2005), Shephard (2008), Bopp, Kaczynski and Besenyi (2012), DeLoach and Tiemann (2012), Ding et al. (2014), Fan, Wen and Kowaleski-Jones (2014), Cass and Faulconbridge (2016), Kai and Haokai (2016), and Gimenez-Nadal and Molina (2019). 


\section{Travel time and time use data}

Time use diaries have become the "gold standard" in the analysis of individual behaviors in recent years (Aguiar and Hurst, 2007; Guryan, Hurst and Kearney, 2008; Gimenez-Nadal and Sevilla, 2012; Harms, Berrigan and Gershuny, 2019), and some authors have found that they produce decreased measurement error and less biased estimates in comparison to stylized-type questions (Bianchi et al., 2000; Bonke, 2005; Yee-Kan, 2008). Time use surveys gather information on daily activities and travel undertaken by individuals and households, and prior literature has relied upon this type of data to analyze commuting (Gimenez-Nadal and Molina, 2016, Gimenez-Nadal, Molina and Velilla, 2018a, 2018b) and travel behaviors (Kitamura and Fujii, 1997, Axhausen et al, 2002; Gerike, Gehlert and Leisch, 2015; Rosales-Salas and Jara-Díaz, 2017; Harms, Gershuny and Olaru, 2018; Aschauer et al., 2019).

Gerike, Gehlert and Leisch (2015) compare travel behavior and activity participation using the German National Travel Survey (NTS) and Time Use Survey (TUS), finding that the number of trips per person is higher in the TUS when changes in location without a trip are included. The daily travel time is consistently higher in the TUS. Thus, time use surveys are an alternative to national travel surveys, and allow for the analysis of travel behavior determinants, including the relationship to non-travel activities, which is the foundation for modelling and policy making. In this context, some authors have considered commuting as all the time spent in the home-to-work (or work-to-home) trip, including the time spent in both commuting and non-commuting episodes (e.g., Horner, 2004). Time use surveys allow for a distinction between "pure" commuting activities and other non-commuting activities that are done during the commuting journey, and thus the conclusions obtained with the use of time use surveys may differ from other studies in terms of total time in commuting, total daily travel, and related activities.

\section{Data and variables}


We use data from the Multinational Time Use Study (MTUS), which is sponsored by the Centre for Time Use Research (CTUR) and is included as part of the Integrated Public Use Microdata Series (IPUMS) of the Institute for Social Research and Data Innovation of the University of Minnesota (Fisher et al., 2019). The MTUS includes detailed time use diaries for a range of countries, along with a series of demographic, economic, and geographic characteristics of respondents. The MTUS provides us with information on individual time use based on diaries, where respondents report their activities during the 24 hours of the day, from 4 am to 4 am of the next day. The diaries include harmonized information about activity location, the mode of transport, and who else was present during the activities. The advantage of 24-hour self-reported diary data over other types of survey collecting transport times, based on stylized questionnaires, is that diaries produce more reliable and accurate estimates (Gimenez-Nadal, Molina and Velilla, 2018a). Thus, time use diaries have become the gold standard in the analysis of worker daily behaviors (Aguiar and Hurst, 2007; Guryan, Hurst and Kearney, 2008; Harms, Berrigan and Gershuny, 2019).

Given that we want to analyze episodes of commuting by workers, we restrict the sample to those between 16 and 65 years old (Aguiar and Hurst, 2007; Gimenez-Nadal and Sevilla, 2012; Gimenez-Nadal, Molina and Velilla, 2018a, 2018b, 2020a). ${ }^{6}$ Respondents who are not in paid work are omitted from the sample, as well as workers who filled their diaries during holidays, to avoid a potential source of bias arising from atypical days. Furthermore, we restrict the analysis to working days, defined as days where respondents devote at least 60 minutes to market work activities, excluding commuting (Gimenez-Nadal, Molina and Velilla, 2018a, 2018b). For the individuals in the sample, we focus on commuting episodes, identified in the MTUS diaries by the code 63 ("travel to/from work"). These restrictions provide a sample of 203,079 commuting episodes, corresponding to 94,517 individuals from seven countries: Canada, Finland, France, South Korea, Spain, the UK, and the US. ${ }^{7}$ (See Table A1 in the Appendix for details on the available years for each of the analyzed countries, the number of individuals, and the number of commuting episodes by country.)

\footnotetext{
${ }^{6}$ Given that retirement age may differ across countries, we select the age limit of 65 years to be consistent with prior studies.

${ }^{7}$ Sample restrictions left 277 (292) episodes of female (male) workers in Hungary. Due to the reduced sample size, Hungary has also been removed from the sample.
} 
We distinguish between episodes of commuting to work, and episodes of commuting from work, considering the location of respondents before these trips. Commuting to work is defined as those trips where the respondent is at home at the beginning of the trip and arrives at the workplace. Conversely, commuting from work is defined as those trips where the respondent is at work at the beginning of the trip and arrives home. ${ }^{8}$ In doing so, we identify commuting time exclusively from the episodes of "travel to/from work", without including any non-commuting activity that is done between the home and the work location. However, we must highlight that some commuting trips may be chained with noncommuting episodes before arriving at work or at home. For instance, a working parent could devote time to a commuting episode followed by picking up children from school, and followed by commuting home. Another worker could combine a commuting episode followed by some leisure (e.g., a visit to the gym), and another commuting episode. In those cases, our definition of the time devoted to/from work includes only the time devoted to commuting episodes, but not the time devoted to other non-commuting activities in between, following pror studies using time use data (Yang and French, 2013; Stone and Schneider, 2016; Gimenez-Nadal, Molina and Velilla, 2018a, 2018b), which may lead to reduced measurement error (see Gimenez-Nadal, Molina and Velilla, 2018a, for a discussion).

For the trips of commuting to and from work, the following characteristics are analyzed. First, we compute the time of day of the commute, in order to analyze the timing of commuting over the working day. Given that there is information on the start time (clock hour) of the trip, and its duration, we know when the trip begins and ends. Second, the duration of commuting trips, measured in minutes per day. Third, we analyze the mode of transport used in the commuting trip. For transport modes, the MTUS includes the following categories: "by car, etc.", "public transport", "walking/on foot", "other physical transport", and "other/unspecified transport". We then classify the episodes of commuting as episodes by private vehicle ("by car, etc.”), in public transport mode ("public transport"), active commuting episodes ("walking/on foot", "other physical transport"), and other transport modes. Our fourth dimension of interest refers to the presence of others while commuting to/from work. The presence of others during commuting can be classified as follows: alone,

\footnotetext{
${ }^{8}$ We must note that the identification of commuting to and from work using location at the beginning and end of the trip may be subject to measurement error, as some trips never started/ended at respondents' workplace/home. However, this measurement error represents less than $0.14 \%$ of the episodes in our sample, indicating that they are a minor concern in our analysis.
} 
with a child, and with the spouse/partner. Finally, for each individual, we compute the number of episodes that add up to a complete trip to/from work.

The MTUS allows us to consider several sociodemographic characteristics of respondents, which have been found to be correlated with commuting behaviors. We first consider the gender of respondents, defined as a dummy that takes value 1 for males, and 0 for females. Given the existing research documenting significant differences in the commuting behaviors of men and women (see Gimenez-Nadal and Molina, 2016, for a recent review), all the analyses and empirical evidence shown here will be done separately by gender. We also consider respondents' age, defined as a continuous variable. The maximum level of formal education achieved by respondents is defined by three dummy variables, identifying individuals who have completed primary education, secondary education, and University education, respectively. The marital status of respondents is defined as a dummy variable that takes value 1 for those who cohabit with a (married or unmarried) partner, and 0 otherwise. Household composition is defined by two variables: the number of individuals in the family unit, and the number of children (aged 17 or under) in the family unit. The hours usually worked per week by respondents are important, given that some authors have found a positive link between work hours and commuting (Gutierrez-i-Puigarnau and van Ommeren, 2010). Finally, we define a dummy variable that identifies part-time workers (value 1, 0 otherwise). (The summary statistics of these variables are shown in Tables A3 and A4 in the Appendix.)

\section{The timing of commuting to and from work}

This Section presents evidence on the timing of commuting trips to and from work. Figure 1 shows, by gender and country, the proportion of individuals commuting during the day, which has twenty-four 1-hour time bands. For each hour on the X-axis, the Y-axis shows the proportion of workers commuting at that time. Figure 1 shows clear differences in the timing of commuting to and from work, consistent with the road pricing and traffic congestion literature (Coria and Zhang, 2015, 2017; Long and Szeto, 2019; Vosough, Poorzahedy and Lindsey, 2020). Furthermore, there are differences across countries, despite that men and women show similar patterns in the timing of commuting. In Canada, about $35 \%$ of male and female workers commute to work between $7 \mathrm{am}$ and $8 \mathrm{am}$, while the rate of 
workers commuting to work in the rest of the day is small (below 5\%, except at noon, with about $5.8 \%$ of males and females commuting to work). Most workers commute from work between $4 \mathrm{pm}$ and $6 \mathrm{pm}$, and these trips seem less concentrated at particular hours, with about $25 \%$ of the workers reporting commuting from work at these hours.

The timing of commuting to work in Finland is different between women and men, as women commuters are highly concentrated between $7 \mathrm{am}$ and $8 \mathrm{am}$, with $33.9 \%$ of women commuting at this hour (vs less than $20 \%$ commuting between $8 \mathrm{am}$ and 9am). Male commutes to work, however, are concentrated between 6am and $8 \mathrm{am}$, with more than $25 \%$ of men commuting to work at these hours. Despite that, the timing of commuting from work is similar, with about $20 \%$ of both women and men commuting from work between $3 \mathrm{pm}$ and $5 \mathrm{pm}$. The timing of commuting to work in South Korea is similar to the figures for Finland, as women commuters are highly concentrated between $8 \mathrm{am}$ and $9 \mathrm{am}(41 \%$ of females), while for men these trips fall between 7am and 9am (with about 38\% of men commuting at these hours). Korean commuters from work are less concentrated at certain hours; women are concentrated between $5 \mathrm{pm}$ and 8pm, with a maximum between $6 \mathrm{pm}$ and $7 \mathrm{pm}$, when $27.6 \%$ of women leave work. The commutes from work of Korean men are roughly the same.

In the UK and the US, the timing of commuting to and from work is qualitatively similar to the timings shown for Finland and South Korea, but with slight differences. For instance, $40.9 \%$ of UK women commute to work between $8 \mathrm{am}$ and 9am, while women in the US commute to work slightly earlier, and more homogeneously, between 7am and 9am $(30.5 \%$ commute to work between $7 \mathrm{am}$ and $8 \mathrm{am}$, and $20.8 \%$ between $8 \mathrm{am}$ and $9 \mathrm{am}$ ). Furthermore, commutes from work among women in both the UK and the US are less concentrated, taking place mostly between $4 \mathrm{pm}$ and $7 \mathrm{pm}$, with the maximum being reached between $5 \mathrm{pm}$ and $6 \mathrm{pm}$ (when $20.4 \%$ of UK women, and $14.4 \%$ of US women are leaving work). Among UK and US men, commutes to work take place essentially between 6am and 9am. In the UK (US), $17.0 \%(21.7 \%)$ of men commute to work between 6am and 7am, 34.1\% (25.7\%) between $7 \mathrm{am}$ and $8 \mathrm{am}$, and $28.9 \%(15.0 \%)$ between $8 \mathrm{am}$ and $9 \mathrm{am}$. Despite the qualitative similarities, the quantitative differences between the UK and the US suggest that commutes to work are more flexible in the US than in the UK. This is supported by the fact that more workers (both men and women) commute to work during the day in the US than in the UK. Regarding commutes from work by men, these are concentrated between $4 \mathrm{pm}$ and $7 \mathrm{pm}$, 
though the maximum percentage is reached between $5 \mathrm{pm}$ and $6 \mathrm{pm}$ (when $26.3 \%$ of UK men and $18.4 \%$ of US men are commuting from work).

Spain and France show certain differences in the timing of commuting to and from work, when compared to the other countries. In these countries, commuting episodes to work, and from work, are concentrated during two periods of the day. Between $30 \%$ and $40 \%$ of workers go to work between $7 \mathrm{am}$ and $9 \mathrm{am}$, but about $15 \%$ also commute to work at $1 \mathrm{pm}$ in France, and between $2 \mathrm{pm}$ and $3 \mathrm{pm}$ in Spain. This is also reflected by the timing of commuting from work, as a similar percentage of French workers commute from work at noon, while about $25 \%$ commute from work between $5 \mathrm{pm}$ and $7 \mathrm{pm}$. In Spain, the timing of commuting from work is different from France, as about $25 \%$ of workers commute from work between $1 \mathrm{pm}$ and $3 \mathrm{pm}$, and between $15 \%$ and $20 \%$ of workers commute from work between $7 \mathrm{pm}$ and $9 \mathrm{pm}$. These differences arise from different job schedules in the countries in the sample, as workdays in France and Spain tend to be split, and Figure 1 suggests that some workers commute from work, to have lunch at home, at midday (about 15\% in France, and between 20 and $25 \%$ in Spain), whereas this is not the case in the other countries analyzed.

These analyses may be useful for the design of road-pricing policies aimed at decreasing traffic congestion or reducing pollution. In Canada, Norway, South Korea, the UK, and the US, road pricing could be designed to affect morning commutes, given that traffic flows are highly concentrated at this time of the day, while road-pricing policies in France and Spain could consider both morning and afternoon commutes to work as being worth including in a congestion and environmental toll (CET) scheme.

\section{The time devoted to commuting to and from work}

In this Section, we focus on the time devoted to commuting to and from work, with a focus on the asymmetries between morning and evening commutes. Table 1 shows average commuting times of workers in the seven countries included in the sample, distinguishing between the times of commuting to work, and commuting from work. We also show differences between women and men, and between the times of commuting to and from work. In Canada, women (men) spend about 45.1 (58.2) minutes per day commuting to/from 
work, of which 25.9 (29.9) are spent commuting to work, and 22.2 (28.2) commuting from work. This produces gender differences (men spend more time than women commuting to and from work), and differences between commutes to and from work (commutes to work last longer than commutes from work, for both women and men), with all the differences being statistically significant at standard levels. ${ }^{9}$ In Finland, women (men) commute about 25.5 (26.3) minutes to work, and 22.9 (24.0) minutes from work, which produces statistically significant differences between commutes, while the raw differences between women and men are not significant (except for commutes from work, which differ between women and men at the 90\% level). French female (male) workers spend about 33.7 (37.6) minutes commuting to work, and 31.9 (35.6) minutes commuting from work. Differences in France are qualitatively similar to those in Canada, as men spend more time than women commuting to and from work, and commutes to work last longer than commutes from work.

Average commuting times in the UK and the US are similar to those in Canada and France, as men commute longer than do women, and the times spent commuting to work are longer than the times commuting from work, for both women and men. The average female (male) worker in the UK spends 28.8 (37.1) minutes commuting to work, and 20.7 (30.6) minutes commuting from work, for a total of 49.5 (67.8) minutes per day. In the US, women (men) spend on average 39.9 (50.4) minutes commuting to/from work, of which 23.4 (27.0) minutes are commutes to work, and 16.4 (23.4) minutes from work. All the differences between women and men are statistically significant at standard levels in the UK and the US.

Commutes in South Korea exhibit differences, compared to the other countries, as we do not find statistically significant variations between the times of commuting to and from work, although we do find that men spend more time commuting to work (36.0 minutes), and from work (36.0), than do women (33.9 and 33.2 minutes, respectively). Results in Spain also present some differences compared to the other countries, in the sense that despite men commuting for longer than women, Spanish workers spend more time commuting from work (29.4 minutes for women, 31.6 minutes for men), than they spend commuting to work (29.6 and 33.3 minutes, respectively), with these differences being statistically significant at standard levels for men.

\footnotetext{
${ }^{9}$ Statistically significant differences are based on t-type tests on the equality of sample means.
} 
In summary, we find that, in most countries, men devote more time to commuting trips than do women. Furthermore, the time devoted to commuting to work is longer than the time devoted to commuting from work in Canada, Finland, France, the UK, and the US, which reveals asymmetries in the duration of morning and evening commuting trips. We next explore whether these asymmetries are related to the mode of transport used.

\section{Differences by mode of transport}

Table 2 shows the average time spent commuting to and from work, by mode of transport, along with the differences between commutes to/from work, and the statistical significance of such differences. ${ }^{10}$

In Canada, the average female worker spends 19.6 (16.8) minutes commuting to (from) work in private vehicle, 4.4 (4.0) minutes commuting on public transport, and 1.7 (1.2) minutes commuting actively. The differences between commutes to and from work are statistically significant in the times of both private vehicle, and active mode of transport, but not in the times spent on public transport. Among males, 24.9 (23.6) minutes are spent in commuting to (from) work in private vehicle, 3.2 (3.0) on public transport, and 1.6 (1.4) actively, with the differences being non-statistically significant, except for the time in private vehicle, which is significant at the $90 \%$ level.

In Finland, the times spent in the different modes of transport considered are not statistically different between to and from work, for all workers. The average female (male) worker commutes to work $14.6(18.9)$ minutes in private vehicle, $1.4(0.4)$ minutes on public transport, and 8.4 (4.1) minutes actively; and the trips from work are about 13.2 (16.9) minutes in private vehicle, 1.4 (1.0) minutes on public transport, and 7.6 (4.2) minutes actively.

Female (male) workers in France spend 23.6 (27.9) minutes commuting to work in private vehicle, 4.1 (3.9) minutes on public transport, and 4.7 (3.8) minutes actively. The commute from work is 21.1 (25.3) minutes in private vehicle, 4.8 (5.0) minutes on public transport, and 4.5 (3.0) minutes actively. The differences among females are statistically significant only for the commuting time in private vehicle, while among male workers all

\footnotetext{
${ }^{10}$ Detailed summary statistics of the commuting episodes are shown in Table A5 in the Appendix.
} 
the differences, in all modes, are significant at standard levels. Furthermore, these differences suggest that commutes to work in private vehicle and active means of transport take longer than commutes from work, while the opposite is found for commuting times on public transport mode.

Korean females spend 11.9 (12.3) minutes commuting to (from) work in private vehicle, 7.6 (7.4) minutes on public transport, and 13.8 (13.0) minutes commuting actively, with this country presenting the longest commutes in active means of transport among the countries analyzed. Differences in the times of commuting to/from work are statistically significant only for the time spent commuting actively. For men, on the other hand, the average time of commuting to (from) work in private vehicle is 22.9 (24.2) minutes, with the difference being statistically significant; 3.4 (3.4) minutes on public transport, with the difference not being significant; and 8.1 (6.5) minutes actively, with the difference being significant at standard levels. Despite that overall differences are not significant for South Korea, Table 2 shows differences depending on the mode of transport, revealing the importance of considering this information when available.

Results in Spain suggest that the times spent commuting to and from work by mode of transport are not statistically different. Women commute to work, on average, about 10.8 minutes by private vehicle, 6.4 minutes on public transport, and 5.6 minutes actively, while their commutes from work are 10.7 minutes in private vehicle, 6.0 minutes in public transport, and 5.2 minutes actively (with the only statistically significant difference being the difference in active commuting to/from work). Among men, the average times of commuting to (from) work are 16.0 (16.1) minutes in private vehicle, 3.4 (3.3) minutes on public transport, and 3.0 (3.1) minutes actively. No significant differences between times to and from work by mode of transport are found among men in Spain.

In the UK, the average female (male) worker commutes to work $17.8(25.4)$ minutes in private vehicle, 4.0 (4.8) minutes on public transport, and 5.5 (4.9) minutes actively, while the return commute is 12.2 (20.4) minutes in private vehicle, 3.1 (4.4) minutes on public transport and 4.2 (4.2) minutes actively. Differences between the times of commuting to and from work are statistically significant for all workers in both private vehicle and active transport, while differences on public transport are significant only for women. 
Finally, in the US, females spend 20.6 (14.2) minutes commuting to (from) work in private vehicle, $1.5(1.3)$ on public transport, and $0.6(0.5)$ actively, with differences between commuting times being statistically significant for private vehicle and active commuting times, but not for public transport mode. The average male commutes 24.0 (20.7) minutes to (from) work in private vehicle, 1.5 (1.6) minutes on public transport, and 0.7 (0.6) minutes actively, with the differences being statistically significant only for the times in private vehicle and active means of transport.

In sum, we find that the differences between the duration of commutes to and from work seem concentrated in commutes by private vehicle (car, truck, motorcycle), where the commutes to work last longer than the commutes from work, among both women and men. There are similar differences in commutes by active means of transport, whereas commuting to and from work by public transport are similar in terms of the time spent. On the other hand, Table 2 suggests that the gender differences in commuting time, where male workers spend more time commuting than do their female counterparts, are congregated in commutes by private vehicle, but not in commutes on public transport or active commuting.

\section{Personal factors associated with asymmetries in commuting time}

All the results reported in Section 5 are raw differences between commuting to work and commuting from work. In this Section, we examine the socio-demographic characteristics (e.g., education, gender) related to asymmetries in the time devoted to commuting to and from work. Our aim is to partially isolate the impact of workers' observed attributes on the difference in worker commuting behavior to and from work. ${ }^{11}$ To that end, we estimate an Ordinary Least Squares (OLS) model as follows:

$$
\log \left(D_{i f}+1\right)=\beta_{c 0}+\beta_{c 1} X_{i c}^{\prime}+\alpha_{c t}+\varepsilon_{i c},
$$

where, for each individual " $i$ " in country " $c$ ", $D i f_{i c}$ represents the difference in commuting, defined as the time of commuting to work, minus the time of commuting from work. A

\footnotetext{
${ }^{11}$ Prior research has documented a variety of unobserved characteristics (e.g., traffic congestion, urban structure, road infrastructure, or the availability of different modes of public transport, among others), along with stochastic factors (e.g., the weather) affecting worker transport behavior and, thus, commuting time. We acknowledge that our analysis may potentially suffer from omitted variable bias.
} 
positive value of this variable indicates that the individual devotes more time to commuting to work than to commuting from work, and a positive coefficient regarding any individual characteristic indicates that this characteristic is related to an asymmetry, in that more time is devoted to commuting to work, in comparison to commuting from work. $X_{i c}$ represents a vector of worker sociodemographic characteristics, $\alpha_{c t}$ represents year and country fixed effects for country " $c$ ", and $\varepsilon_{i c}$ represents unmeasured factors. We pool all the countries to explore whether there are systematic cross-country differences in commuting asymmetries, net of the effect of socio-demographic characteristics. ${ }^{12}$ All the estimates include sample weights provided by the MTUS data, and robust standard errors clustered at the country level. The set of socio-demographic characteristics included in $X_{i c}$ includes those described in Section 3.

Columns (1) and (2) of Table 3 show estimation results for Equation (1), estimated separately for women and men. We observe a statistically significant correlation between worker age and the difference in commuting to/from work time, which follows an invertedU shape. The results also reveal a positive and statistically significant correlation between worker education and the commuting difference, which is about 10.5 (10.9) percent larger for female (male) workers with secondary education than for similar respondents with primary education, while for those with University education this difference increases to about 28.6 (24.4) percent. This suggests that there is a greater asymmetry in commuting to/from work behaviors among workers with higher formal education levels. Regarding household composition, individuals who cohabit as a (married or unmarried) couple show shorter commuting differences, while family size is not statistically significant for either women or men. However, women's commuting differences are correlated with the number of children in the household in a statistically significant way, since the more children there are in the household, the larger the difference in the times devoted to commuting to and from work.

Regarding labor attributes, the results show that the number of hours worked per week is not correlated with commuting differences, even when prior research has found that commuting behaviors are linked to labor supply (Gutierrez-i-Puigarnau and van Ommeren,

\footnotetext{
12 The guidelines developed by the Center for Time Use Research to harmonize time use surveys makes variables included in the MTUS highly comparable, allowing cross-country comparison of similar sets of socio-demographic characteristics.
} 
2010). This suggests that the link between commuting time and paid work hours is similar for commutes both to and from work, thus making the correlation with the commuting difference not statistically significant at standard levels. On the other hand, the commuting asymmetry among female part-time workers is smaller than among female full-time workers, while that correlation is not statistically significant for males.

For the modes of transport used, estimates show that for men who commute by private vehicle or actively, the difference tends to be smaller. Those who commute by public transport report larger differences, net of observed heterogeneity, in commuting to/from work times.

We now estimate Equation (1) omitting country fixed effects and including instead a set of indices, defined at the country-year level, related to factors associated with commuting behavior. These indices, obtained from the World Bank Database, serve as proxies for transport infrastructure, road security, travel behavior, economic growth, and urban distribution, all of which have been identified as determinants of commuting time (Naess, 2003, 2006, 2009; Santos et al., 2013; Mitra and Saphores, 2019; Gimenez-Nadal, Molina and Velilla, 2020a). Specifically, we consider the number of passengers carried by railway, multiplied by kilometers traveled (divided by 1,000), and the length of railway routes available for train service (divided by 1,000), as national indices for transport infrastructure availability. We also include the mortality caused by road traffic injury, defined as deaths per 100,000 population. We consider the percentage growth of per capita GDP, as a proxy for national income, and also the $\mathrm{CO} 2$ emissions from liquid fuel consumption (measured in $\mathrm{kt}$ ), as prior research has found a link between travel behaviors and $\mathrm{CO} 2$ emissions. For urban distribution at the country level, we include the percentage of people living in urban areas, as defined by national statistical offices.

Columns (3) and (4) of Table 3 show estimates of Equation (1) when we include this set of national indices. The main coefficients associated with the set of worker attributes (coefficients $\beta_{c 1}$ ) are similar (both qualitatively and quantitatively) in Columns (1-2), and Columns (3-4), and we conclude that the impact of these national indices in the main estimates does not affect the conditional correlation between the commuting differences and worker socioeconomic observable factors. Furthermore, we observe that better transport infrastructure, measured by the number of railway passengers, is correlated with greater 
differences in commuting to/from work. Similarly, countries with more of their population living in urban areas are correlated with greater commuting differences. Similar results are found for the amount of $\mathrm{CO} 2$ emissions, and the rates of GDP growth (with the latter being statistically significant only for women). Traffic mortality is correlated with shorter differences in commuting to/from work times.

Finally, we estimate Equation (1) separately for each of the countries in the sample, in order to determine whether there are differences among countries in the conditional correlations between the dependent variable and the set of explanatory variables. Again, robust standard errors are computed. These estimates are shown in Table 4. Columns (1) and (2) show the main coefficients for women and men in Canada, respectively. Estimates show a non-statistically significant correlation between age and the commuting difference among women, while the correlation is significant for men, in an inverted U-shaped relationship. Individuals with University education, both women and men, report more time to work (relative to time from work), compared to those with only primary or secondary education. On the other hand, workers who cohabit with a partner report smaller commuting differences. Women part-time workers report shorter differences, and differences are larger among women on weekdays than on working-weekend days. The corresponding coefficients are not statistically significant among men. Regarding transport modes, both women and men who commute more by either private vehicle or public transport report larger commuting to/from work gaps than those who commute more actively or by other means of transport.

Columns (3) and (4) show the results for Finnish workers. No sociodemographic variables are found to be statistically significant among women, while for men only age is significant at standard levels, revealing an inverted U-shaped relationship with the commuting to/from work difference. Nevertheless, the results reveal a significant increase in the commuting difference among individuals who commute by public transport. Columns (5) and (6) show the results for France, and none of the sociodemographic and transport mode variables are found to be statistically significant, with the only exception being women's weekly work hours, suggesting that women who work longer have a greater commuting to/from work difference. 
Columns (7) and (8) show the estimates for South Korea. Age is not significant for women, but is correlated with the commuting to/from work difference following an inverted-U shape. Education, on the other hand, is not significant among men, but shows a positive correlation with the commuting difference among women. Family size is also positively correlated with commuting to/from work differences for both women and men, while the number of children shows a negative correlation, which is only significant at standard levels for men. Women's work hours are negatively correlated with the commuting difference. Women who commute by private vehicle or active commuting report more time from work, relative to the time of commuting to work, while the opposite is true for men who commute by public transport.

Results for Spain are shown in Columns (9) and (10). Among women, no sociodemographic variables are estimated to be statistically significant. Among men, on the other hand, results show that those with University education report a smaller commuting to/from work gap. Family size, the number of children, and being a part-time worker are positively correlated with the commuting difference to/from work. Regarding transport modes, commuting by private vehicle or public transport is correlated with a larger commuting difference, while more active commuting is oppositely correlated to the difference in commuting.

Results for UK workers are shown in Columns (11) and (12). Age is again correlated with the commuting to/from work difference, following an inverted-U shape, but that is statistically significant at standard levels only among women. Household composition is correlated with commuting to/from work differences, but only among women, with the number of household members showing a negative correlation, but the number of children a positive correlation. Regarding labor attributes, being a part-time worker is correlated with smaller differences in commuting to/from work, with the corresponding coefficient being statistically significant for men but not for women. In terms of transport modes, results show that both men and women who commute by public transport report greater differences in their commuting times to/from work.

Columns (13) and (14) of Table 4 show the results for the US. Age shows an invertedUshaped correlation with the difference in commuting to/from work, with coefficients being significant at standard levels for both women and men. Education is positively correlated 
with the commuting difference, for both women and men, and cohabiting in a couple is negatively correlated, with the coefficients being highly significant. Family size and the number of children are negative, and positively correlated with the commuting difference, but with the former only being significant for women. The number of working hours and the part-/full-time status are not significant at standard levels, and differences in the commuting to/from work are greater on weekdays than during weekend working days. Those who commute by private vehicle, or actively, report smaller differences in commuting to/from work (although the coefficient associated with private vehicle commuting is only significant for men), while the opposite is the case for those who commute by public transport.

All in all, Table 4 shows a mixture of results, and some conclusions can be only tentatively derived. First, estimates reveal different correlations between the set of explanatory variables, and the differences in commuting times, which appear both across and within countries (and different coefficients for men and women in each country). This result is in line with prior research documenting commuting as a complex transport phenomenon, where unobservable and/or stochastic characteristics have a strong impact on worker commuting trips (Burger et al., 2011; van Acker and Witlox, 2011; Ma et al., 2017; Gimenez-Nadal, Molina and Velilla, 2018a, 2020a). This is also reflected in the $R^{2}$ associated with the estimates, which is low and in line with the research (van Ommeren and van der Straaten, 2008; Ross and Zenou, 2008). The results are also consistent with works documenting gender differences in commuting time (Gimenez-Nadal and Molina, 2016). Second, there appear to be differences in commuting to work, and commuting from work, that are partially explained by worker characteristics. Table 4 suggests the existence of a significant connection between the differences in commuting to/from work, and the mode of transport, a connection that is non-robust across countries. The use of public transport generates longer times of commuting to work, relative to shorter times from work, in all the countries but France. However, commuting by private vehicle has mixed effects on commuting differences, which may be explained by transport infrastructures. This particular connection is left for future research, using alternative data sources.

\section{Discussion}


The analysis presented here may be useful for researchers in different fields. For instance, the fact that there are asymmetries in commuting to and from work, and that such differences vary by gender, geographic location, and mode of transport, may imply that policies that are used to regulate traffic (e.g., road-pricing) should be designed to account for such differences. For instance, if women present, in comparison to men, larger asymmetries in commuting time, perhaps road-pricing policies are less effective for this group of workers. Furthermore, in South Korea we find that there are no asymmetries in commuting time, and thus, perhaps road-pricing policies should be applied to all commuting, while they have traditionally focused only on morning commutes. The responses to these questions, and to many others that refer to transport and planning policies, should be addressed in future research.

As a starting point, our results for the timing of commuting to and from work suggest that in Canada, Norway, South Korea, the UK, and the US, road pricing could be designed to apply to morning commutes, given that traffic flows are highly concentrated at this time of the day, but those policies in France and Spain could consider both morning and afternoon commutes, to be part of a congestion and environmental toll (CET) scheme. Furthermore, our analysis of the mode of transport reveals that asymmetries are mainly concentrated in the use of private cars, but only in Canada, France, the UK, and the US. These cross-country differences may indicate that road-pricing policies are less effective in countries where asymmetries in commuting by private car are not present, or they may also reflect that roadpricing policies are better designed in the latter countries, as morning commutes are less subject to traffic congestion. These questions, and others that may emerge (e.g., do roadpricing policies lead to increased use of public transport, or more carpooling?), should be addressed in future research.

The fact that we find cross-country differences in asymmetries in commuting time calls for possible explanations within the geographic context. Population density, degree of urbanization, and city size are factors related to the commuting behavior of workers. The explanation within the geographic context would allow researchers and policy makers to have a better idea of what new knowledge brings that was missing in the commuting literature ignoring asymmetries. Moreover, differences in the socio-demographic characteristics of workers have been found to explain part of the asymmetries in the duration of commuting and in the mode of transport used. Knowing how socio-demographic 
characteristics intersect with the geographic context would help to explain differences in workers' commuting behaviors. Similarly, the reported differences in the times of commuting to and from work, and the moderating role of transport modes in those differences, should also be taken into account by researchers and planners. If the use of public transport is associated with more asymmetries in commuting to and from work, this may indicate a component of public transport unpredictability that may be detrimental for its use, a very important implication for environmental issues.

Prior research on commuting has suggested that the relationship between commuting behaviors and stress should be revisited, as it may be that only commutes to work, but not from work, generate stress. In a similar context, longer commuting time produces increased shirking behaviors at work and reduced productivity. However, our results suggest that this relationship may be different if commutes to work, or from work, are studied separately, given that the trips are not symmetric. The correlation between commuting and feelings while commuting could also be revisited, differentiating between commutes to work, and commutes from work. Further analysis should also focus on differences in the composition of all commuting. On theoretical grounds, our results are also relevant because asymmetries in commuting length or modes of transport may imply that excess commuting refers to specific trips to work or from work, or it may depend on the time of the day (e.g., excess commuting is different in the morning than in the evening) or depends on the mode of transport. Similarly, if commutes are not symmetric, it would be important to distinguish between extreme trips to work and from work, and to analyze the differences between them.

Our definition of commuting to and from work contrasts with the fact that some authors have considered commuting as all the time spent in the home-to-work (or work-to-home) trip, including the time spent in both commuting and non-commuting episodes (e.g., Horner, 2004). Thus, the consideration of non-commuting episodes as part of the commuting trip is an important issue. In order to see to what extent this issue biases our results, we compare commuting times in both contexts (including and not including non-commuting episodes), with intermediate activities addressed in Table A2 in the Appendix, compared with results shown in Table 1, when non-commuting activities are not included in the analysis. Differences between Tables 1 and A2 then show the potential bias that may arise from the different definitions of commuting from time use diaries. For all the countries in the sample, gender differences in commuting to and from work remain qualitatively unchanged. 
Furthermore, when including intermediate activities, differences between the times of commuting to work and from work remain qualitatively unchanged in Finland, South Korea, the UK, and the US. Conversely, this changes in the case of females in Canada, and males in France and Spain, suggesting that in these countries the activities that workers do within their commuting journeys are different in their commutes to and from work, which reinforces the idea of commutes not being symmetric. A detailed analysis of this topic (i.e., the ancillary activities that workers do while commuting to/from work) is left for further research.

Finally, we highlight the importance of time use surveys in the analysis of worker commuting behaviors in particular, and individuals' travel behavior in general. We have shown that these surveys may be analyzed in terms of different commuting episodes (to/from work, by transport mode, with or without others, etc.), and even different commuting definitions. This enriches the study of commuting, relative to other surveys that include only stylized questions on commuting time during regular workdays (e.g., the Panel Study of Income Dynamics, the European Working Conditions Survey, and the British Household Panel Survey).

Time Use Surveys have certain limitations. For instance, to the best of our knowledge, no Time Use Survey covers longitudinal information, as these are cross-sectional databases. Thus, the analyses using time use diaries are limited to conditional correlations analysis, as the lack of a panel-data structure prevents authors from proposing causal analyses. Another limitation is that, with the exception of the American Time Use Survey of the US, time use surveys are not annual surveys. Given their relevance for social, transport, and economic applied research, planners should encourage national statistical offices to promote these databases. Another limitation of these types of data is that they are defined at the individual level in certain countries, whereas several time-use decisions (including commuting) may be the outcome of a household bargaining interaction between spouses or household members (Kato and Matsumoto, 2009; Roberts, Hodgson and Dolan, 2011; Carta and De Philippis, 2018; Hong, Lee and McDonald, 2018). Thus, time use surveys prevent the analysis of joint decisions in the household (i.e., the analysis of joint commuting is limited to the perspective of just the interviewed spouse). 


\section{Conclusions}

This paper analyzes asymmetries in the commuting behavior of individuals when they commute from home to work, and from work to home. These journeys are often considered identical in both applied research and theoretical models, but the topic has received little attention in the combination of the dimensions of timing and mode of transport. Using detailed time use diaries from the MTUS data, for the last two decades and seven countries, we find that, in general terms, commutes to work last longer than commutes from work, for both women and men, but with quantitative country differences, and commutes to work are more concentrated at certain hours than commutes from work. Furthermore, there appear to be differences in commuting times that are partially explained by worker characteristics. We find a significant connection between the differences in commuting to/from work, and the mode of transport, although this correlation is not heterogeneous across countries. The use of public transport generates longer times of commuting to work, relative to times of commuting from work, in all the countries but France. However, commuting by private vehicle has mixed effects on commuting differences, which may be explained by differences in transport infrastructures.

The analysis has certain limitations. For instance, it represents a first exploration of the differences between commuting to work and from work, using detailed time use diaries. The databases are cross-sectional, thus preventing us from analyzing any kind of causal links (i.e., the results must be understood as conditional correlations). Similarly, we cannot deal with potential endogeneity. Finally, commuting times are a complex phenomenon that has been linked to stochastic and non-controllable factors, such as traffic congestion and weather conditions (see van Ommeren and van der Straaten, 2008, for a summary). Despite these limitations, our results may serve as a starting point for future research on this topic, and may also help urban planners and policy makers in the design of mobility policies, such as road pricing, or updated public transport systems.

\section{References}

Aguiar, M., \& Hurst, E. (2007). Measuring trends in leisure: The allocation of time over five decades. The Quarterly Journal of Economics, 122(3), 969-1006. 
Albert, J. F., Casado-Díaz, J. M., \& Simón, H. (2019). The commuting behaviour of selfemployed workers: Evidence for Spain. Papers in Regional Science, 98(6), 2455-2477.

Alonso, W. (1964). Location and Land Use Harvard University Press. Cambridge, MA.

Aschauer, F., Rösel, I., Hössinger, R., Kreis, H. B., \& Gerike, R. (2019). Time use, mobility and expenditure: an innovative survey design for understanding individuals' trade-off processes. Transportation, 46(2), 307-339.

Axhausen, K. W., Zimmermann, A., Schönfelder, S., Rindsfüser, G., \& Haupt, T. (2002). Observing the rhythms of daily life: A six-week travel diary. Transportation, 29(2), 95124.

Bai, X., Zhai, W., Steiner, R. L., \& He, Z. (2020). Exploring extreme commuting and its relationship to land use and socioeconomics in the central Puget Sound. Transportation Research Part D: Transport and Environment, 88, 102574.

Bianchi, S. M., Milkie, M. A., Sayer, L. C., \& Robinson, J. P. (2000). Is anyone doing the housework? Trends in the gender division of household labor. Social Forces, 79(1), 191228.

Bleviss, D. L. (2021). Transportation is critical to reducing greenhouse gas emissions in the United States. Wiley Interdisciplinary Reviews: Energy and Environment, 10(2), e390.

Bonke, J. (2005). Paid work and unpaid work: Diary information versus questionnaire information. Social Indicators Research, 70(3), 349-368.

Bopp, M., Kaczynski, A. T., \& Besenyi, G. (2012). Active commuting influences among adults. Preventive Medicine, 54(3-4), 237-241.

Burd, C., Burrows, M., and McKenzie, B. (2021). "Travel Time to Work in the United States: 2019," American Community Survey Reports, ACS-47, U.S. Census Bureau, Washington, DC.

Burger, M. J., de Goei, B., Van der Laan, L., \& Huisman, F. J. (2011). Heterogeneous development of metropolitan spatial structure: Evidence from commuting patterns in English and Welsh city-regions, 1981-2001. Cities, 28(2), 160-170.

Carta, F., \& De Philippis, M. (2018). You've come a long way, baby. Husbands' commuting time and family labour supply. Regional Science and Urban Economics, 69, 25-37. 
Cass, N., \& Faulconbridge, J. (2016). Commuting practices: New insights into modal shift from theories of social practice. Transport Policy, 45, 1-14.

Cavallaro, F., \& Dianin, A. (2019). Cross-border commuting in Central Europe: features, trends and policies. Transport Policy, 78, 86-104.

Champion, T., Coombes, M., \& Brown, D. L. (2009). Migration and longer-distance commuting in rural England. Regional Studies, 43(10), 1245-1259.

Chatterjee, K., Chng, S., Clark, B., Davis, A., De Vos, J., Ettema, D., \& Reardon, L. (2020). Commuting and wellbeing: a critical overview of the literature with implications for policy and future research. Transport Reviews, 40(1), 5-34.

Chiappori, P. A. (1988). Rational household labor supply. Econometrica, 56(1), 63-90.

Chiappori, P. A. (1992). Collective labor supply and welfare. Journal of Political Economy, 100(3), 437-467.

Chiappori, P. A., de Palma, A., Inoa, I., \& Picard, N. (2014). Residential location choice and household decision. Mimeo, Columbia University.

Christian, T. J. (2012). Automobile commuting duration and the quantity of time spent with spouse, children, and friends. Preventive Medicine, 55(3), 215-218.

Connolly, M. (2008). Here comes the rain again: Weather and the intertemporal substitution of leisure. Journal of Labor Economics, 26(1), 73-100.

Connolly M (2018) Climate change and the allocation of time. IZA World of Labor 2018: 417.

Coria, J., \& Zhang, X. B. (2015). State-dependent enforcement to foster the adoption of new technologies. Environmental and Resource Economics, 62(2), 359-381.

Coria, J., \& Zhang, X. B. (2017). Optimal environmental road pricing and daily commuting patterns. Transportation Research Part B: Methodological, 105, 297-314.

Crane, R. (2007). Is there a quiet revolution in women's travel? Revisiting the gender gap in commuting. Journal of the American Planning Association, 73(3), 298-316.

Cropper, M. L., \& Gordon, P. L. (1991). Wasteful commuting: A re-examination. Journal of Urban Economics, 29(1), 2-13. 
Cutler, D. M., \& Glaeser, E. L. (1997). Are ghettos good or bad? The Quarterly Journal of Economics, 112(3), 827-872.

Dargay, J. M., \& Clark, S. (2012). The determinants of long distance travel in Great Britain. Transportation Research Part A: Policy and Practice, 46(3), 576-587.

Dargay, J., \& Hanly, M. (2007). Volatility of car ownership, commuting mode and time in the UK. Transportation Research Part A: Policy and Practice, 41(10), 934-948.

Dargay, J. M., \& van Ommeren, J. (2005, August). The effect of income on commuting time using panel data. In 45th Conference of the European Regional Science Association.

De Palma, A., Inoa, I., \& Picard, N. (2014). Discrete choice decision-making with multiple decision-makers within the household. In Handbook of Choice Modelling. Edward Elgar Publishing.

De Palma, A., Lindsey, R., \& Picard, N. (2015). Trip-timing decisions and congestion with household scheduling preferences. Economics of Transportation, 4(1-2), 118-131.

Deding, M., Filges, T., \& Van Ommeren, J. (2009). Spatial mobility and commuting: The case of two-earner households. Journal of Regional Science, 49(1), 113-147.

DeLoach, S. B., \& Tiemann, T. K. (2012). Not driving alone? American commuting in the twenty-first century. Transportation, 39(3), 521-537.

Dex, S., Clark, A., \& Taylor, M. (1995). Household labour supply. Research Series No. 43. Sheffield: Employment Department.

Dickerson, A., Hole, A. R., \& Munford, L. A. (2014). The relationship between well-being and commuting revisited: Does the choice of methodology matter? Regional Science and Urban Economics, 49, 321-329.

Ding, D., Gebel, K., Phongsavan, P., Bauman, A. E., \& Merom, D. (2014). Driving: a road to unhealthy lifestyles and poor health outcomes. PloS One, 9(6), e94602.

European Commission (2019). Commuting between regions. Report WDN-20190806-1.

Fan, J. X., Wen, M., \& Kowaleski-Jones, L. (2014). An ecological analysis of environmental correlates of active commuting in urban US. Health \& Place, 30, 242-250.

Fisher, K., Gershuny, J., Flood, S. M., Backman, D., \& Hofferth, S. L. (2019). Multinational Time Use Study Extract System: Version 1.3 [dataset]. Minneapolis, MN: IPUMS. 
Gallo, M., \& Marinelli, M. (2020). Sustainable mobility: A review of possible actions and policies. Sustainability, 12, 7499.

Garreau, J. (1991). Edge City: Life on the New Frontier. Doubleday, New York.

Gerike, R., Gehlert, T., \& Leisch, F. (2015). Time use in travel surveys and time use surveysTwo sides of the same coin? Transportation Research Part A: Policy and Practice, 76, 4-24.

Gershenson, C. (2013). Living in living cities. Artificial Life, 19(3-4), 401-420.

Gimenez-Nadal, J. I., \& Molina, J. A. (2014). Commuting time and labour supply in the Netherlands: A time use study. Journal of Transport Economics and Policy, 48(3), 409426.

Gimenez-Nadal, J. I., \& Molina, J. A. (2016). Commuting time and household responsibilities: Evidence using propensity score matching. Journal of Regional Science, 56(2), 332-359.

Gimenez-Nadal, J. I., \& Molina, J. A. (2019). Daily feelings of US workers and commuting time. Journal of Transport \& Health, 12, 21-33.

Gimenez-Nadal, J. I., Molina, J. A., \& Velilla, J. (2018a). The commuting behavior of workers in the United States: Differences between the employed and the self-employed. Journal of Transport Geography, 66(1), 19-29.

Gimenez-Nadal, J. I., Molina, J. A., \& Velilla, J. (2018b). Spatial distribution of US employment in an urban efficiency wage setting. Journal of Regional Science, 58(1), 141-158.

Gimenez-Nadal, J. I., Molina, J. A., \& Velilla, J. (2019). Modelling commuting time in the US: Bootstrapping techniques to avoid overfitting. Papers in Regional Science, 98(4), 1667-1684.

Giménez-Nadal, J. I., Molina, J. A., \& Velilla, J. (2020a). Commuting and self-employment in Western Europe. Journal of Transport Geography, 88, 102856.

Giménez-Nadal, J. I., Molina, J. A., \& Velilla, J. (2020b). Testing urban efficiency wages in France and Spain. Empirical Economics, forthcoming. 
Gimenez-Nadal, J. I., \& Sevilla, A. (2012). Trends in time allocation: A cross-country analysis. European Economic Review, 56(6), 1338-1359.

Gobillon, L., Selod, H., \& Zenou, Y. (2007). The mechanisms of spatial mismatch. Urban Studies, 44(12), 2401-2427.

Gordon, P., Kumar, A., \& Richardson, H. W. (1989). The spatial mismatch hypothesis: Some new evidence. Urban Studies, 26(3), 315-326.

Grieco, M., Pickup, L., \& Whipp, R. (1989). Gender, transport and employment: The impact of travel constraints. Aldershot: Gower Publishing Company.

Grinza, E., \& Rycx, F. (2020). The impact of sickness absenteeism on firm productivity: new evidence from Belgian matched employer-employee panel data. Industrial Relations, 59(1), 150-194.

Guirao, B., Campa, J. L., \& Casado-Sanz, N. (2018). Labour mobility between cities and metropolitan integration: The role of high speed rail commuting in Spain. Cities, 78, 140-154.

Guryan, J., Hurst, E., \& Kearney, M. (2008). Parental education and parental time with children. Journal of Economic Perspectives, 22(3), 23-46.

Gutiérrez-i-Puigarnau, E., \& van Ommeren, J. N. (2010). Labour supply and commuting. Journal of Urban Economics, 68(1), 82-89.

Gutiérrez-i-Puigarnau, E., Mulalic, I., \& Van Ommeren, J. N. (2016). Do rich households live farther away from their workplaces? Journal of Economic Geography, 16(1), 177201.

Habib, K. M. N. (2012). Modeling commuting mode choice jointly with work start time and work duration. Transportation Research Part A: Policy and Practice, 46(1), 33-47.,

Hamilton, B. W. (1982). Wasteful commuting. Journal of Political Economy, 90(5), 10351053.

Hamilton, B. W. (1989). Wasteful commuting again. Journal of Political Economy, 97(6), 1497-1504.

Hanson, S. \& Johnston, I. (1985). Gender differences in work trip lengths: Implications and explanations. Urban Geography, 6(3), 193-219. 
Harms, T., Berrigan, D., \& Gershuny, J. (2019). Daily metabolic expenditures: estimates from US, UK and polish time-use data. BMC Public Health, 19(2), 453.

Harms, T., Gershuny, J., \& Olaru, D. (2018). Using time-use data to analyse travel behaviour: Findings from the UK. Transportation Research Procedia, 32, 634-648.

Hilbrecht, M., Smale, B., \& Mock, S. E. (2014). Highway to health? Commute time and well-being among Canadian adults. World Leisure Journal, 56(2), 151-163.

Hong, S. H., Lee, B. S., \& McDonald, J. F. (2018). Commuting time decisions for twoworker households in Korea. Regional Science and Urban Economics, 69, 122-129.

Horner, M. W. (2002). Extensions to the concept of excess commuting. Environment and Planning A: Economy and Space, 34(3), 543-566.

Horner, M. W. (2004). Spatial dimensions of urban commuting: a review of major issues and their implications for future geographic research. The Professional Geographer, 56(2), 160-173.

Hu, L. (2021). Gender differences in commuting travel in the US: interactive effects of race/ethnicity and household structure. Transportation, 48(2), 909-929.

Hu, L., \& Schneider, R. J. (2017). Different ways to get to the same workplace: How does workplace location relate to commuting by different income groups? Transport Policy, 59, 106-115.

Humphreys, D. K., Goodman, A., \& Ogilvie, D. (2013). Associations between active commuting and physical and mental wellbeing. Preventive Medicine, 57(2), 135-139.

Iwata, S., \& Tamada, K. (2014). The backward-bending commute times of married women with household responsibility. Transportation, 41(2), 251-278.

Jacob, N., Munford, L., Rice, N., \& Roberts, J. (2021). Does commuting mode choice impact health? Health Economics, 30(2), 207-230.

Jessoe, K., Manning, D. T., \& Taylor, J. E. (2018). Climate change and labour allocation in rural Mexico: Evidence from annual fluctuations in weather. The Economic Journal, 128(608), 230-261.

Jin, J. (2019). The effects of labor market spatial structure and the built environment on commuting behavior: Considering spatial effects and self-selection. Cities, 95, 102392. 
Johnston, I. (1992). The influence of household type on gender differences in work trip distance. The Professional Geographer, 44(2), 161-169.

Jones, P., Massot, M. H., Orfeuil, J. P., \& Proulhac, L. (2008). Links between daily travel times and lifestyles of families: Paris and London. Rapport Final de Contrat Pour La Fédération Internationale Automobile (FIA Foundation), février.

Kahn, M. E. (2000). The environmental impact of suburbanization. Journal of Policy Analysis and Management, 19(4), 569-586.

Kahneman, D., \& Krueger, A. B. (2006). Developments in the measurement of subjective well-being. Journal of Economic Perspectives, 20(1), 3-24.

Kai, C., \& Haokai, L. (2016). Factors affecting consumers' green commuting. Eurasia Journal of Mathematics, Science and Technology Education, 12(3), 527-538.

Kain, J. F. (1962). The journey-to-work as a determinant of residential location. Papers and Proceedings of the Regional Science Association, 9: 137-160

Kato, H., \& Matsumoto, M. (2009). Intra-household interaction in a nuclear family: A utilitymaximizing approach. Transportation Research Part B: Methodological, 43(2), 191203.

Kim, K., \& Horner, M. W. (2021). Examining the impacts of the Great Recession on the commuting dynamics and jobs-housing balance of public and private sector workers. Journal of Transport Geography, 90, 102933.

Kirby, D. K., \& LeSage, J. P. (2009). Changes in commuting to work times over the 1990 to 2000 period. Regional Science and Urban Economics, 39(4), 460-471.

Kitamura, R., Fujii, S., \& Pas, E. I. (1997). Time-use data, analysis and modeling: toward the next generation of transportation planning methodologies. Transport Policy, 4(4), 225-235.

Knox, P. L., \& McCarthy, L. (2005). Urbanization: an introduction to urban geography. Upper Saddle River, NJ: Pearson Prentice Hall.

Krüger, J. J., \& Neugart, M. (2018). Weather and Intertemporal Labor Supply: Results from German Time-Use Data. Labour, 32(1), 112-140. 
Kunn-Nelen, A. (2016). Does commuting affect health? Health Economics, 25(8), 9841004.

Le Barbanchon, T., Rathelot, R., \& Roulet, A. (2019). Gender differences in job search: Trading off commute against wage. SSRN 3467750.

Lee, B. S., \& McDonald, J. F. (2003). Determinants of commuting time and distance for Seoul residents: The impact of family status on the commuting of women. Urban Studies, 40(7), 1283-1302.

Long, J., \& Szeto, W. Y. (2019). Congestion and environmental toll schemes for the morning commute with heterogeneous users and parallel routes. Transportation Research Part B: Methodological, 129, 305-333.

Ma, K. R., \& Banister, D. (2006). Excess commuting: A critical review. Transport Reviews, 26(6), 749-767.

Ma, X., Liu, C., Wen, H., Wang, Y., \& Wu, Y. J. (2017). Understanding commuting patterns using transit smart card data. Journal of Transport Geography, 58, 135-145.

Manaugh, K., Miranda-Moreno, L. F., \& El-Geneidy, A. M. (2010). The effect of neighbourhood characteristics, accessibility, home-work location, and demographics on commuting distances. Transportation, 37(4), 627-646.

Manning, A. (2003). The real thin theory: Monopsony in modern labour markets. Labour Economics, 10(2), 105-131.

Maoh, H., \& Tang, T. (2012). Determinants of normal and extreme commute distance in a sprawled midsize Canadian city: evidence from Windsor, Canada. Journal of Transport Geography, 25, 50-57.

Marion, B., \& Horner, M. W. (2007). Comparison of socioeconomic and demographic profiles of extreme commuters in several US metropolitan statistical areas. Transportation Research Record, 2013(1), 38-45.

Martin, A., Goryakin, Y., \& Suhrcke, M. (2014). Does active commuting improve psychological wellbeing? Longitudinal evidence from eighteen waves of the British Household Panel Survey. Preventive Medicine, 69, 296-303. 
McKenzie, B., \& Rapino, M. (2009). Commuting in the United States: 2009. Washington, DC: US Department of Commerce, Economics and Statistics Administration, US Census Bureau.

McKim, L. (2014). The economic geography of active commuting: Regional insights from Wellington, New Zealand. Regional Studies, Regional Science, 1(1), 88-95.

McQuaid, R. W. (2009). A model of the travel to work limits of parents. Research in Transportation Economics, 25(1), 19-28.

McQuaid, R. W., \& Chen, T. (2012). Commuting times: The role of gender, children and part-time work. Research in Transportation Economics, 34(1), 66-73.

Mieszkowski, P., \& Mills, E. S. (1993). The causes of metropolitan suburbanization. Journal of Economic Perspectives, 7(3), 135-147.

Mills, E. S. (1967). An aggregative model of resource allocation in a metropolitan area. American Economic Review, 57(2), 197-210.

Mitra, S. K., \& Saphores, J. D. M. (2019). Why do they live so far from work? Determinants of long-distance commuting in California. Journal of Transport Geography, 80, 102489.

Mok, D. (2007). Do two-earner household base their choice of residential location on both incomes? Urban Studies, 44(4), 723-750.

Molina, J. A., Giménez-Nadal, J. I., \& Velilla, J. (2020). Sustainable commuting: Results from a social approach and international evidence on carpooling. Sustainability, 12(22), 9587.

Moss, J. E., Jack, C. G., \& Wallace, M. T. (2004). Employment location and associated commuting patterns for individuals in disadvantaged rural areas in Northern Ireland. Regional Studies, 38(2), 121-136.

Mulalic, I., Van Ommeren, J. N., \& Pilegaard, N. (2014). Wages and commuting: Quasinatural experiments' evidence from firms that relocate. The Economic Journal, 124(579), 1086-1105.

Muller, P.O. (1981). Contemporary Suburban America. Prentice Hall, NJ.

Muth, R.F. (1969). Cities and Housing: The Spatial Pattern of Urban Residential Land Use. University of Chicago Press, Chicago, IL. 
Naess, P. (2003). Urban structures and travel behaviour. European Journal of Transport and Infrastructure Research, 3(2), 155-178.

Naess, P. (2006). Urban structure matters: residential location, car dependence and travel behaviour. Routledge.

Naess, P. (2009). Residential self-selection and appropriate control variables in land use: Travel studies. Transport Reviews, 29(3), 293-324.

Naess, P., Strand, A., Wolday, F., \& Stefansdottir, H. (2019). Residential location, commuting and non-work travel in two urban areas of different size and with different center structures. Progress in Planning, 128, 1-36.

Naess, P., Tønnesen, A., \& Wolday, F. (2019). How and why does intra-metropolitan workplace location affect car commuting? Sustainability, 11(4), 1196.

Nafilyan, V. (2019). Gender differences in commute time and pay: A study into the gender gap for pay and commuting time, using data from the Annual Survey of Hours and Earnings. Office for National Statistics, United Kingdom.

O’Kelly, M. E., Niedzielski, M. A., \& Gleeson, J. (2012). Spatial interaction models from Irish commuting data: variations in trip length by occupation and gender. Journal of Geographical Systems, 14(4), 357-387.

Oakil, A. T. M., Nijland, L., \& Dijst, M. (2016). Rush hour commuting in the Netherlands: Gender-specific household activities and personal attitudes towards responsibility sharing. Travel Behaviour and Society, 4, 79-87.

Oswald, A. J., Proto, E., \& Sgroi, D. (2015). Happiness and productivity. Journal of Labor Economics, 33(4), 789-822.

Picard, N., Dantan, S., \& De Palma, A. (2018). Mobility decisions within couples. Theory and Decision, 84(2), 149-180.

Picard, N., de Palma, A., \& Dantan, S. (2014). Couple mode choice, car ownership and bargaining power. International Workshop On Current Topics In Choice Modelling, Leeds, June 2014.

Plaut, P. O. (2005). Non-motorized commuting in the US. Transportation Research Part D: Transport and Environment, 10(5), 347-356. 
Roberts, J., Hodgson, R., \& Dolan, P. (2011). It's driving her mad: Gender differences in the effects of commuting on psychological health. Journal of Health Economics, 30(5), 1064-1076.

Rodríguez, D. A. (2004). Spatial choices and excess commuting: A case study of bank tellers in Bogotá, Colombia. Journal of Transport Geography, 12(1), 49-61.

Rosales-Salas, J., \& Jara-Díaz, S. (2017). Beyond transport time: A review of time use modeling. Transportation Research Part A: Policy and Practice, 97, 209-230.

Ross, S. L., \& Zenou, Y. (2008). Are shirking and leisure substitutable? An empirical test of efficiency wages based on urban economic theory. Regional Science and Urban Economics, 38(5), 498-517.

Rouwendal, J., \& Nijkamp, P. (2004). Living in two worlds: A review of home-to-work decisions. Growth and Change, 35(3), 287-303.

Sandow, E. (2008). Commuting behaviour in sparsely populated areas: evidence from northern Sweden. Journal of Transport Geography, 16(1), 14-27.

Sandow, E., Westerlund, O., \& Lindgren, U. (2014). Is your commute killing you? On the mortality risks of long-distance commuting. Environment and Planning A, 46(6), 14961516.

Sandow, E., \& Westin, K. (2010). Preferences for commuting in sparsely populated areas: The case of Sweden. Journal of Transport and Land Use, 2(3/4), 87-107.

Santos, G., Maoh, H., Potoglou, D., \& von Brunn, T. (2013). Factors influencing modal split of commuting journeys in medium-size European cities. Journal of Transport Geography, 30(1), 127-137.

Sevilla, A., Gimenez-Nadal, J. I., \& Gershuny, J. (2012). Leisure inequality in the United States: 1965-2003. Demography, 49(3), 939-964.

Shengxiao, L., \& Pegnjun, Z. (2015). The determinants of commuting mode choice among school children in Beijing. Journal of Transport Geography, 46, 112-121.

Shephard, R. J. (2008). Is active commuting the answer to population health? Sports Medicine, 38(9), 751-758. 
Small, K. A., \& Song, S. (1992). Wasteful commuting: A resolution. Journal of Political Economy, 100(4), 888-898.

Smith, S. V. (2017). Exploring BME commuting students' experiences: Sharing practice for inclusive curricular change and institutional action. In: RAISE2017, 06 September 2017 - 08 September 2017, Manchester.

Stone and Schneider, 2016 Stone, A. A., \& Schneider, S. (2016). Commuting episodes in the United States: Their correlates with experiential wellbeing from the American Time Use Survey. Transportation Research Part F: Traffic Psychology and Behaviour, 42, 117-124.

Sun, B., Ermagun, A., \& Dan, B. (2017). Built environmental impacts on commuting mode choice and distance: Evidence from Shanghai. Transportation Research Part D: Transport and Environment, 52, 441-453.

Susilo, Y. O., \& Maat, K. (2007). The influence of built environment to the trends in commuting journeys in the Netherlands. Transportation, 34(5), 589-609.

Tajalli, M., \& Hajbabaie, A. (2017). On the relationships between commuting mode choice and public health. Journal of Transport \& Health, 4, 267-277.

Train, K., \& McFadden, D. (1978). The goods/leisure tradeoff and disaggregate work trip mode choice models. Transportation Research, 12(5), 349-353.

Turner, T., \& Niemeier, D. (1997). Travel to work and household responsibility: New evidence. Transportation, 24(4), 397-419.

Van Acker, V., \& Witlox, F. (2011). Commuting trips within tours: how is commuting related to land use? Transportation, 38(3), 465-486.

Van Ommeren, J. N., \& Gutiérrez-i-Puigarnau, E. (2011). Are workers with a long commute less productive? An empirical analysis of absenteeism. Regional Science and Urban Economics, 41(1), 1-8.

Van Ommeren, J. N., \& Van der Straaten, J. W. (2008). The effect of search imperfections on commuting behavior: Evidence from employed and self-employed workers. Regional Science and Urban Economics, 38(2), 127-147. 
Vincent-Geslin, S., \& Ravalet, E. (2016). Determinants of extreme commuting. Evidence from Brussels, Geneva and Lyon. Journal of Transport Geography, 54, 240-247.

Vosough, S., Poorzahedy, H., \& Lindsey, R. (2020). Predictive cordon pricing to reduce air pollution. Transportation Research Part D: Transport and Environment, 88, 102564.

Walks, A. (Ed.). (2014). The urban political economy and ecology of automobility: Driving cities, driving inequality, driving politics. Routledge.

Wener, R. E., Evans, G. W., Phillips, D., Nadler, N. (2003). Running for the 7:45: The effects of public transit improvements on commuter stress. Transportation, 30, 203-220.

White, M. J. (1986). Sex differences in urban commuting patterns. American Economic Review, 76(2), 368-372.

White, M. J. (1988). Urban commuting journeys are not "wasteful". Journal of Political economy, 96(5), 1097-1110.

Yang, J., \& French, S. (2013). The Travel-Obesity Connection: Discerning the Impacts of Commuting Trips with the Perspective of Individual Energy Expenditure and Time Use. Environment and Planning B: Planning and Design, 40(4), 617-629.

Yang, L., Hipp, J. A., Adlakha, D., Marx, C. M., Tabak, R. G., \& Brownson, R. C. (2015). Choice of commuting mode among employees: Do home neighborhood environment, worksite neighborhood environment, and worksite policy and supports matter? Journal of Transport \& Health, 2(2), 212-218.

Yee-Kan, M. (2008). Measuring housework participation: The gap between "stylised" questionnaire estimates and diary-based estimates. Social Indicators Research, 86(3), 381-400.

Zenou, Y. (2006). Efficiency wages and unemployment in cities: The case of high-relocation costs. Regional Science and Urban Economics, 36(1), 49-71.

Zenou, Y. (2009). Urban labor economics. Cambridge University Press. 
Figure 1. The timing of commuting to/from work

Canada - women

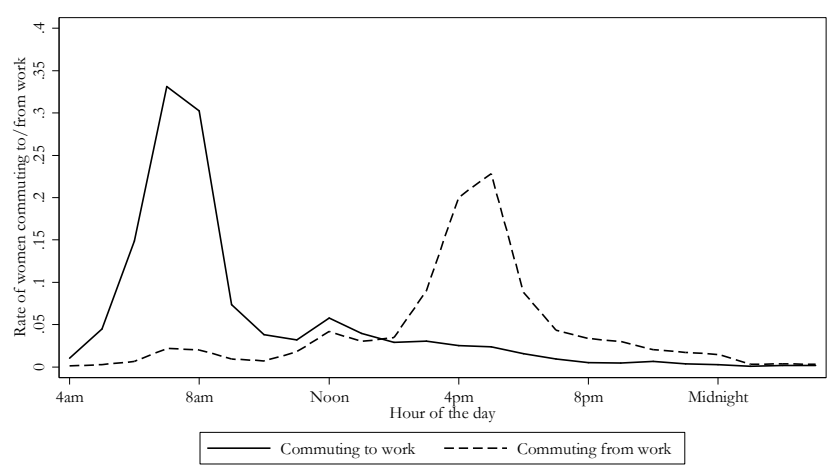

Finland - women

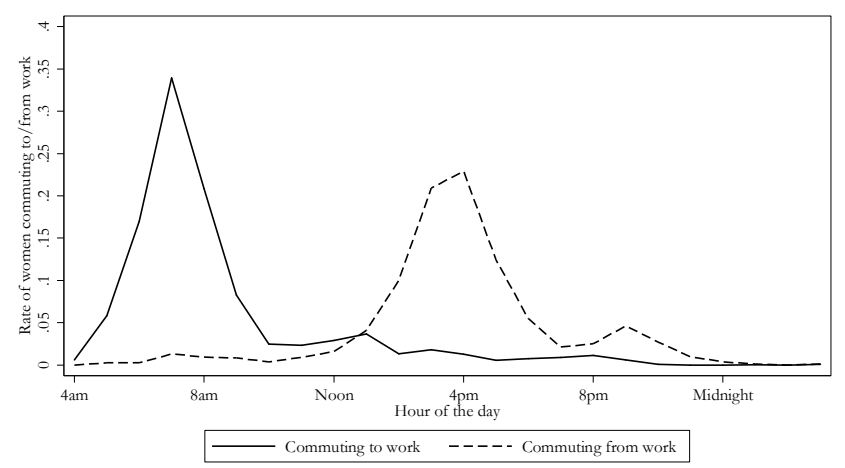

France - women

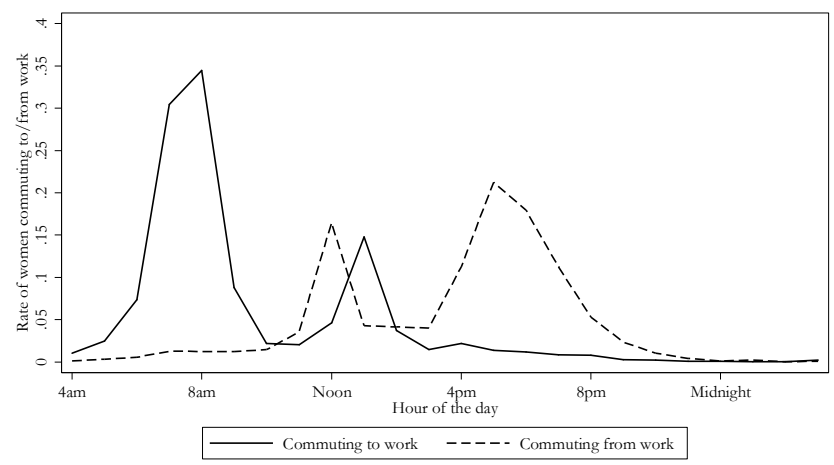

South Korea - women

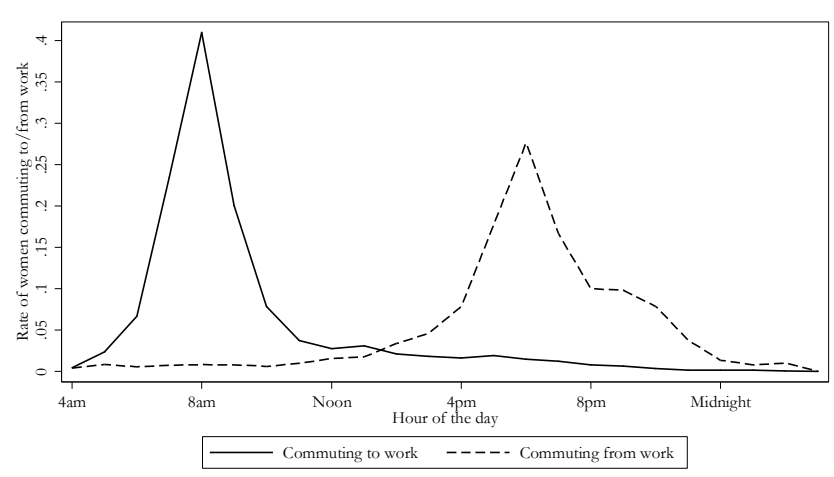

Canada - men

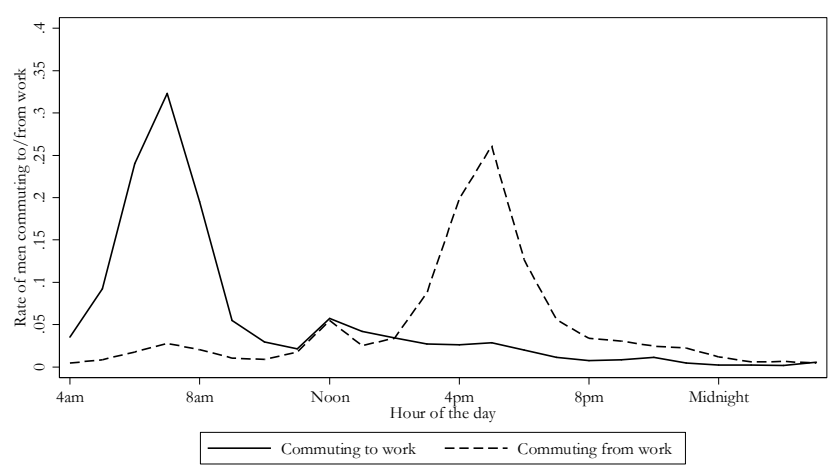

Finland - men

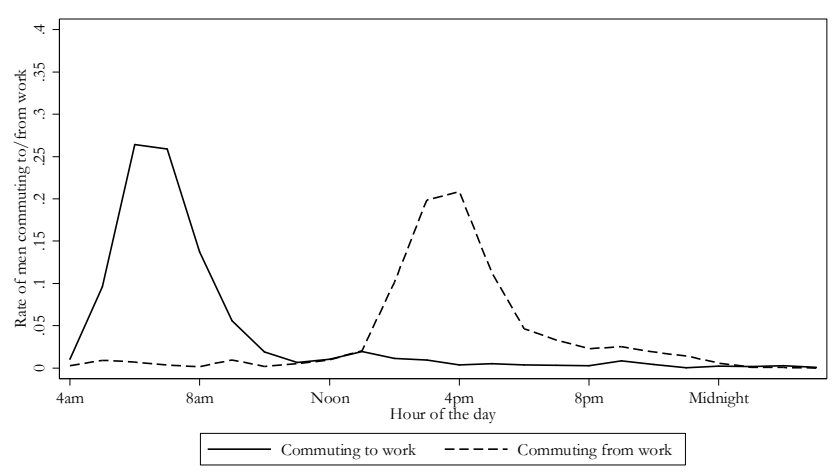

France - men

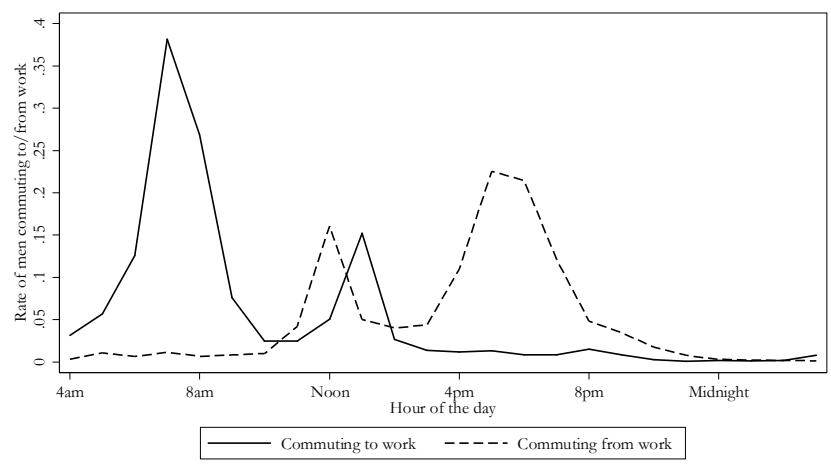

South Korea - men

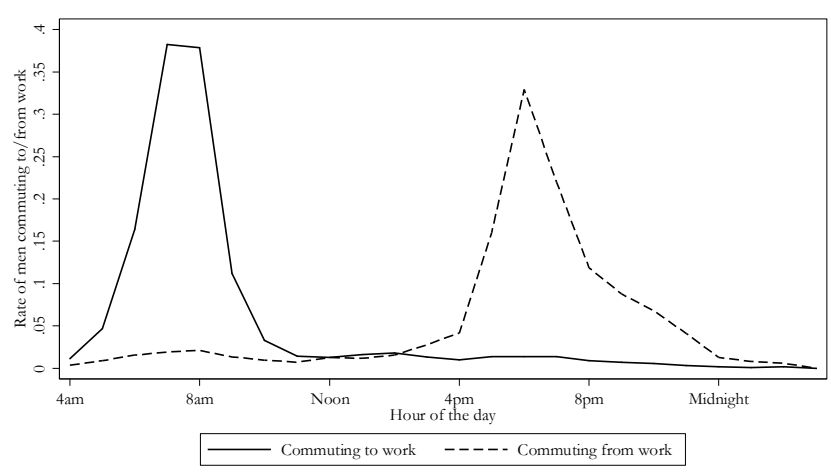


Figure 1 (Cont.). The timing of commuting to/from work

Spain - women

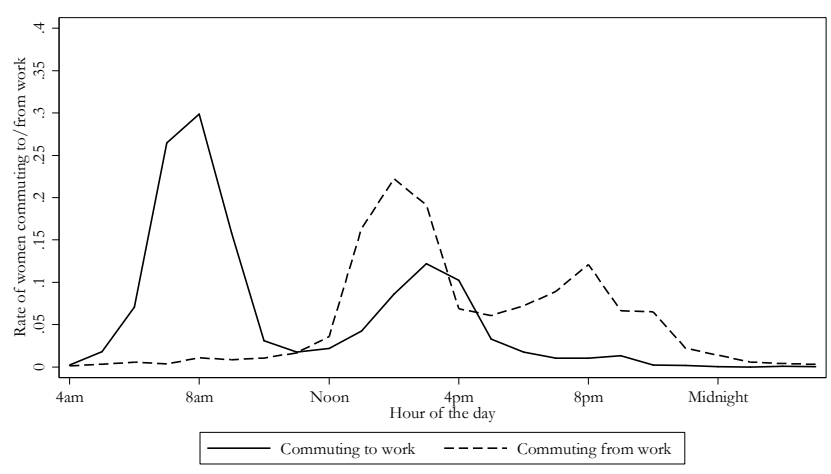

UK - women

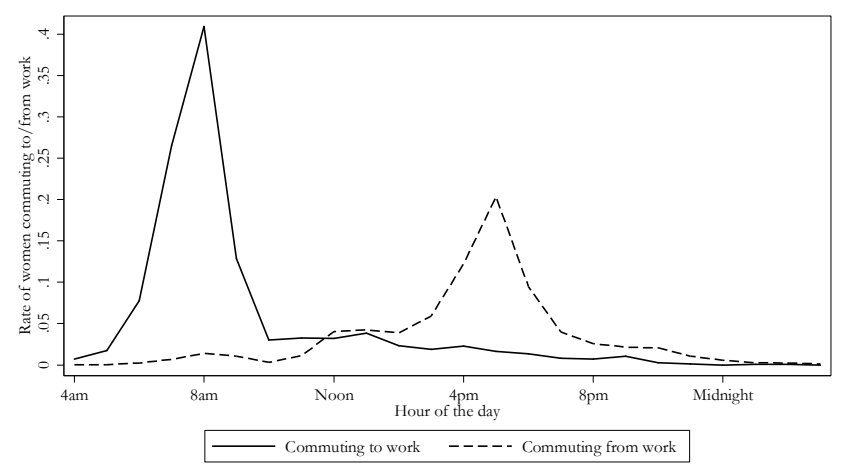

US - women

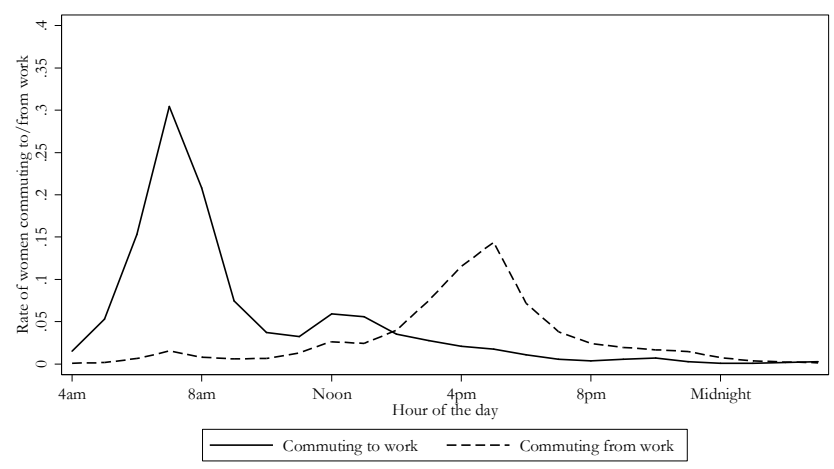

Spain - men

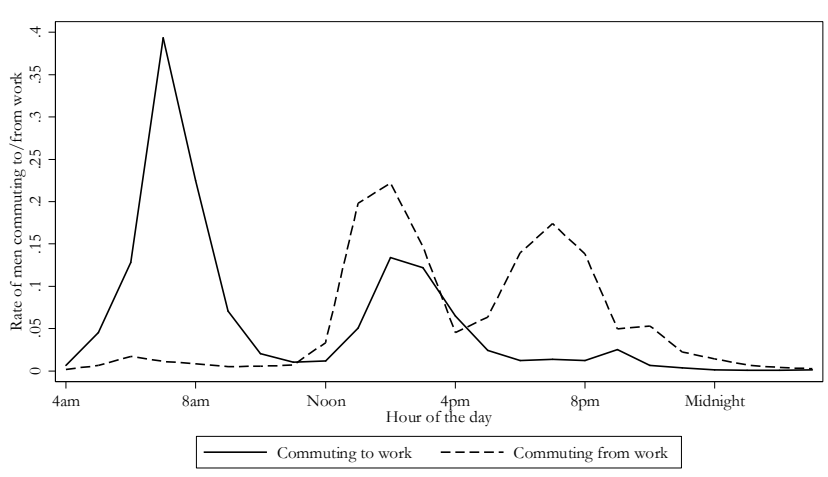

UK - men

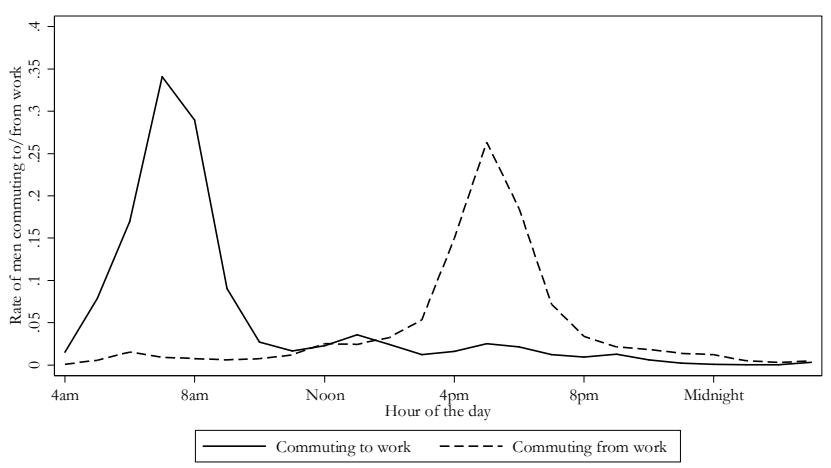

US - men

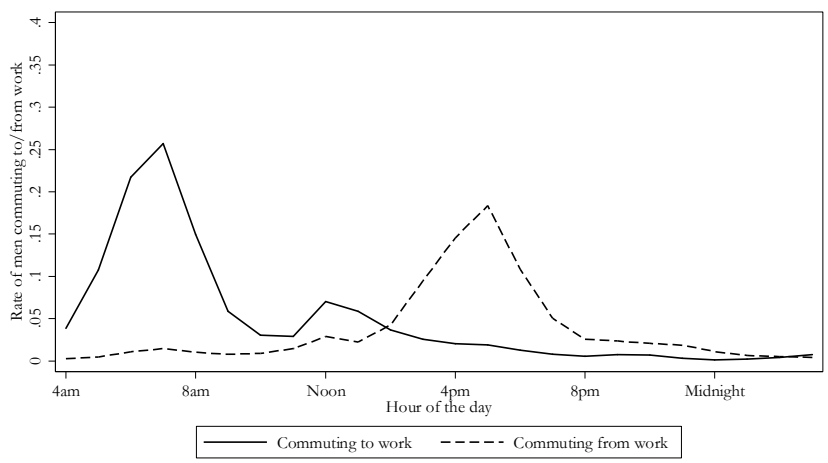

Note: The sample (MTUS 2000-2018) has been restricted to countries with non-missing information on the main variables. The sample includes employed individuals who worked the diary day. The commuting time for the whole sample, and detailed information on the percentage of male and female individuals commuting to/from work is shown in Table A6 in the Appendix. 
Table 1. Average time of commuting to and from work

\begin{tabular}{|c|c|c|c|c|c|c|}
\hline \multirow[b]{2}{*}{ Country } & \multirow[b]{2}{*}{ Sex } & \multicolumn{4}{|c|}{ Commuting time } & \multirow{2}{*}{$\begin{array}{c}\text { No. } \\
\text { Individuals }\end{array}$} \\
\hline & & Total & To work & From work & Difference & \\
\hline \multirow[t]{3}{*}{ Canada } & Women & 48.055 & 25.883 & 22.172 & $3.711 * * *$ & 4,913 \\
\hline & Men & 58.164 & 29.936 & 28.229 & $1.707 * *$ & 4,999 \\
\hline & Gender diff. & $-10.109 * * *$ & $-4.053 * * *$ & $-6.057 * * *$ & & \\
\hline \multirow[t]{3}{*}{ Finland } & Women & 48.390 & 25.460 & 22.930 & $2.530 * * *$ & 722 \\
\hline & Men & 50.319 & 26.270 & 24.049 & $2.221 *$ & 609 \\
\hline & Gender diff. & -1.929 & -0.810 & $-1.119 *$ & & \\
\hline \multirow[t]{3}{*}{ France } & Women & 65.563 & 33.704 & 31.859 & $1.845 * *$ & 2,466 \\
\hline & Men & 73.190 & 37.552 & 35.638 & $1.914 *$ & 2,599 \\
\hline & Gender diff. & $-7.627 * * *$ & $-3.848 * * *$ & $-3.779 * * *$ & & \\
\hline \multirow[t]{3}{*}{ South Korea } & Women & 67.117 & 33.888 & 33.229 & 0.659 & 5,440 \\
\hline & Men & 71.989 & 35.996 & 35.993 & 0.003 & 8,137 \\
\hline & Gender diff. & $-4.872 * * *$ & $-2.108 * * *$ & $-2.764 * * *$ & & \\
\hline \multirow[t]{3}{*}{ Spain } & Women & 59.048 & 29.409 & 29.639 & -0.230 & 4,994 \\
\hline & Men & 64.861 & 31.573 & 33.289 & $-1.716^{* * *}$ & 6,823 \\
\hline & Gender diff. & $-5.813 * * *$ & $-2.164 * * *$ & $-3.650 * * *$ & & \\
\hline \multirow[t]{3}{*}{ UK } & Women & 49.525 & 28.828 & 20.697 & $8.131 * * *$ & 2,652 \\
\hline & Men & 67.761 & 37.128 & 30.633 & $6.495 * * *$ & 2,817 \\
\hline & Gender diff. & $-18.236 * * *$ & $-8.300 * * *$ & $-9.936 * * *$ & & \\
\hline \multirow[t]{3}{*}{ US } & Women & 39.892 & 23.448 & 16.444 & $7.004 * * *$ & 22,603 \\
\hline & Men & 50.369 & 26.999 & 23.370 & $3.629 * * *$ & 24,743 \\
\hline & Gender diff. & $-10.477 * * *$ & $-3.551 * * *$ & $-6.926 * * *$ & & \\
\hline
\end{tabular}

Note: Standard deviations available upon request. The sample (MTUS 2000-2018) has been restricted to countries with non-missing information on the main variables. The sample includes employed individuals who worked the diary day. Commuting time is measured in minutes. Differences in commuting time to/from work are computed as the time of commuting to work, minus the time of commuting from work. Differences between women and men are computed as the average time of women, minus the average time of men. * Significant at the $90 \%$ level; ** significant at the $95 \%$ level; *** significant at the $99 \%$ level; all computed according to $t$ type tests. 
Table 2. Average time of commuting to and from work, by mode of transport

\begin{tabular}{|c|c|c|c|c|c|c|c|}
\hline \multirow[b]{2}{*}{ Country } & \multirow[b]{2}{*}{ Mode } & \multicolumn{3}{|c|}{ Women } & \multicolumn{3}{|c|}{ Men } \\
\hline & & To work & From work & Difference & To work & From work & Difference \\
\hline \multirow[t]{3}{*}{ Canada } & Private vehicle & 19.617 & 16.817 & $2.800 * * *$ & 24.911 & 23.612 & $1.299 *$ \\
\hline & Public transport & 4.370 & 4.020 & 0.350 & 3.155 & 2.962 & 0.193 \\
\hline & Active & 1.699 & 1.225 & $0.474 * * *$ & 1.605 & 1.382 & 0.223 \\
\hline \multirow[t]{3}{*}{ Finland } & Private vehicle & 14.556 & 13.151 & 1.405 & 18.866 & 16.870 & 1.996 \\
\hline & Public transport & 1.402 & 1.396 & 0.006 & 0.447 & 0.960 & -0.513 \\
\hline & Active & 8.361 & 7.590 & 0.771 & 4.123 & 4.208 & -0.085 \\
\hline \multirow[t]{3}{*}{ France } & Private vehicle & 23.638 & 21.131 & $2.507 * * *$ & 27.935 & 25.312 & $2.623 * * *$ \\
\hline & Public transport & 4.076 & 4.767 & -0.691 & 3.942 & 4.984 & $-1.042 * *$ \\
\hline & Active & 4.670 & 4.503 & 0.167 & 3.830 & 3.010 & $0.820 * *$ \\
\hline \multirow[t]{3}{*}{ South Korea } & Private vehicle & 11.939 & 12.349 & -0.410 & 22.911 & 24.182 & $-1.271 * * *$ \\
\hline & Public transport & 7.642 & 7.423 & 0.219 & 3.443 & 3.449 & -0.006 \\
\hline & Active & 13.845 & 13.006 & $0.839 * *$ & 8.054 & 6.524 & $1.530 * * *$ \\
\hline \multirow[t]{3}{*}{ Spain } & Private vehicle & 10.756 & 10.748 & 0.008 & 16.043 & 16.062 & -0.019 \\
\hline & Public transport & 6.387 & 6.036 & 0.351 & 3.379 & 3.314 & 0.065 \\
\hline & Active & 5.633 & 5.229 & $0.404 *$ & 3.006 & 3.098 & -0.092 \\
\hline \multirow[t]{3}{*}{ UK } & Private vehicle & 17.829 & 12.196 & $5.633 * * *$ & 25.397 & 20.415 & $4.982 * * *$ \\
\hline & Public transport & 3.979 & 3.119 & $0.860 * *$ & 4.767 & 4.425 & 0.342 \\
\hline & Active & 5.501 & 4.154 & $1.347 * * *$ & 4.936 & 4.167 & $0.769 * *$ \\
\hline \multirow[t]{3}{*}{ US } & Private vehicle & 20.636 & 14.191 & $6.445 * * *$ & 24.026 & 20.658 & $3.368 * * *$ \\
\hline & Public transport & 1.473 & 1.341 & 0.132 & 1.512 & 1.580 & -0.068 \\
\hline & Active & 0.639 & 0.451 & $0.188 * * *$ & 0.744 & 0.574 & $0.170 * * *$ \\
\hline
\end{tabular}

Note: Standard deviations available upon request. The sample (MTUS 2000-2018) has been restricted to countries with non-missing information on the main variables. The sample includes employed individuals who worked the diary day. Commuting time is measured in minutes. Private vehicle includes car, truck, or motorcycle. Active commuting includes walking and physical modes of transport. Other trips are classified as "unspecified". Differences in commuting time to/from work are computed as the time of commuting to work, minus the time of commuting from work. * Significant at the $90 \%$ level; ** significant at the $95 \%$ level; *** significant at the $99 \%$ level; all computed according to $t$-type tests. 
Table 3. Estimates on the differences in commuting to/from work

\begin{tabular}{|c|c|c|c|c|}
\hline \multirow[b]{3}{*}{ VARIABLES } & \multicolumn{2}{|c|}{ FIXED EFFECTS } & \multicolumn{2}{|c|}{ NATIONAL INDICES } \\
\hline & (1) & (2) & (3) & (4) \\
\hline & Women & Men & Women & Men \\
\hline \multicolumn{5}{|l|}{ Sociodemographics } \\
\hline Age & $\begin{array}{c}0.020 \text { *** } \\
(0.006)\end{array}$ & $\begin{array}{c}0.031 * * * \\
(0.006)\end{array}$ & $\begin{array}{c}0.020 * * * \\
(0.006)\end{array}$ & $\begin{array}{c}0.032^{* * *} \\
(0.006)\end{array}$ \\
\hline Age squared & $\begin{array}{c}-0.026^{* * *} \\
(0.007)\end{array}$ & $\begin{array}{c}-0.035^{* * *} \\
(0.007)\end{array}$ & $\begin{array}{c}-0.027 * * * \\
(0.007)\end{array}$ & $\begin{array}{c}-0.036^{* * * *} \\
(0.007)\end{array}$ \\
\hline Education: secondary & $\begin{array}{c}0.105 * * * \\
(0.031)\end{array}$ & $\begin{array}{c}0.108 * * * \\
(0.029)\end{array}$ & $\begin{array}{c}0.105 * * * \\
(0.031)\end{array}$ & $\begin{array}{c}0.109^{* * * *} \\
(0.030)\end{array}$ \\
\hline Education: University & $\begin{array}{c}0.289 * * * \\
(0.031)\end{array}$ & $\begin{array}{c}0.245 * * * \\
(0.029)\end{array}$ & $\begin{array}{c}0.286 * * * \\
(0.031)\end{array}$ & $\begin{array}{c}0.244 * * * \\
(0.029)\end{array}$ \\
\hline Married/cohabiting & $\begin{array}{c}-0.116^{* * * *} \\
(0.023)\end{array}$ & $\begin{array}{c}-0.141^{* * *} \\
(0.026)\end{array}$ & $\begin{array}{c}-0.116^{* * *} \\
(0.023)\end{array}$ & $\begin{array}{c}-0.136^{* * *} \\
(0.026)\end{array}$ \\
\hline Family size & $\begin{array}{l}-0.011 \\
(0.012)\end{array}$ & $\begin{array}{c}0.003 \\
(0.012)\end{array}$ & $\begin{array}{l}-0.006 \\
(0.012)\end{array}$ & $\begin{array}{c}0.009 \\
(0.012)\end{array}$ \\
\hline Number of children & $\begin{array}{c}0.052^{* * *} \\
(0.015)\end{array}$ & $\begin{array}{l}0.026^{*} \\
(0.014)\end{array}$ & $\begin{array}{c}0.045 * * * \\
(0.015)\end{array}$ & $\begin{array}{c}0.020 \\
(0.014)\end{array}$ \\
\hline Weekly work hours & $\begin{array}{c}0.001 \\
(0.001)\end{array}$ & $\begin{array}{c}0.001 \\
(0.001)\end{array}$ & $\begin{array}{c}0.001 \\
(0.001)\end{array}$ & $\begin{array}{c}0.001 \\
(0.001)\end{array}$ \\
\hline Part-time worker & $\begin{array}{c}-0.067 * * \\
(0.028)\end{array}$ & $\begin{array}{c}0.016 \\
(0.044)\end{array}$ & $\begin{array}{c}-0.053^{*} \\
(0.028)\end{array}$ & $\begin{array}{c}0.027 \\
(0.044)\end{array}$ \\
\hline Weekday & $\begin{array}{c}0.226 * * * \\
(0.022)\end{array}$ & $\begin{array}{c}0.157 * * * \\
(0.021)\end{array}$ & $\begin{array}{c}0.224 * * * \\
(0.022)\end{array}$ & $\begin{array}{c}0.154 * * * \\
(0.021)\end{array}$ \\
\hline \multicolumn{5}{|l|}{ Transport mode } \\
\hline Rate: private vehicle & $\begin{array}{c}-0.006 \\
(0.034)\end{array}$ & $\begin{array}{c}-0.070^{*} \\
(0.038)\end{array}$ & $\begin{array}{c}-0.018 \\
(0.033)\end{array}$ & $\begin{array}{c}-0.083^{* *} \\
(0.038)\end{array}$ \\
\hline Rate: public transport & $\begin{array}{c}0.571 * * * \\
(0.054)\end{array}$ & $\begin{array}{c}0.532 * * * \\
(0.065)\end{array}$ & $\begin{array}{c}0.573 * * * \\
(0.054)\end{array}$ & $\begin{array}{c}0.526^{* * *} \\
(0.065)\end{array}$ \\
\hline Rate: active & $\begin{array}{c}-0.098^{* * *} \\
(0.035)\end{array}$ & $\begin{array}{c}-0.207 * * * \\
(0.047)\end{array}$ & $\begin{array}{c}-0.094 * * * \\
(0.033)\end{array}$ & $\begin{array}{c}-0.201 * * * \\
(0.047)\end{array}$ \\
\hline \multicolumn{5}{|l|}{ National indices } \\
\hline Passenger railways & - & - & $\begin{array}{c}0.033 * * * \\
(0.005)\end{array}$ & $\begin{array}{c}0.031^{* * * *} \\
(0.005)\end{array}$ \\
\hline Railways length (km) & - & - & $\begin{array}{c}-0.006 \\
(0.010)\end{array}$ & $\begin{array}{c}-0.004 \\
(0.010)\end{array}$ \\
\hline Perc. urban population & - & - & $\begin{array}{c}0.055^{* * *} \\
(0.012)\end{array}$ & $\begin{array}{c}0.034 * * * \\
(0.013)\end{array}$ \\
\hline Traffic mortality & - & - & $\begin{array}{c}-0.081 * * * \\
(0.013)\end{array}$ & $\begin{array}{c}-0.041 \text { *** } \\
(0.013)\end{array}$ \\
\hline GDP growth & - & - & $\begin{array}{c}0.063 * * * \\
(0.016)\end{array}$ & $\begin{array}{c}0.023 \\
(0.017)\end{array}$ \\
\hline $\mathrm{CO} 2$ transport emission & - & - & $\begin{array}{c}0.043 * * * \\
(0.010)\end{array}$ & $\begin{array}{c}0.024 * * \\
(0.010)\end{array}$ \\
\hline Constant & $\begin{array}{c}0.429 * * * \\
(0.160)\end{array}$ & $\begin{array}{l}0.279^{*} \\
(0.167)\end{array}$ & $\begin{array}{c}-3.372 * * * \\
(0.984)\end{array}$ & $\begin{array}{l}-1.870^{*} \\
(1.039)\end{array}$ \\
\hline Country F.E. & Yes & Yes & No & No \\
\hline Year F.E. & Yes & Yes & Yes & Yes \\
\hline Observations & 33,103 & 35,920 & 33,103 & 35,920 \\
\hline R-squared & 0.048 & 0.031 & 0.047 & 0.030 \\
\hline
\end{tabular}

Note: The sample (MTUS 2000-2018) has been restricted to countries with nonmissing information on the main variables. The sample includes employed individuals who worked the diary day. The dependent variable is the log-of-minutes of the difference between commuting to and from work. * Significant at the $90 \%$ level; ** significant at the $95 \%$ level; *** significant at the $99 \%$ level. 
Table 4. Results by country

\begin{tabular}{|c|c|c|c|c|c|c|c|c|c|c|c|c|c|c|}
\hline \multirow[b]{3}{*}{ VARIABLES } & \multicolumn{2}{|c|}{ CANADA } & \multicolumn{2}{|c|}{ FINLAND } & \multicolumn{2}{|c|}{ FRANCE } & \multicolumn{2}{|c|}{ SOUTH KOREA } & \multicolumn{2}{|c|}{ SPAIN } & \multicolumn{2}{|c|}{ UK } & \multicolumn{2}{|c|}{ US } \\
\hline & (1) & (2) & (3) & (4) & (5) & (6) & (7) & (8) & (9) & (10) & $(11)$ & (12) & (13) & (14) \\
\hline & Women & Men & Women & Men & Women & Men & Women & Men & Women & Men & Women & Men & Women & Men \\
\hline \multicolumn{15}{|l|}{ Sociodemographics } \\
\hline Age & $\begin{array}{c}0.000 \\
(0.015)\end{array}$ & $\begin{array}{c}0.040^{* *} \\
(0.016)\end{array}$ & $\begin{array}{l}-0.033 \\
(0.049)\end{array}$ & $\begin{array}{c}0.108^{* *} \\
(0.053)\end{array}$ & $\begin{array}{c}0.020 \\
(0.031)\end{array}$ & $\begin{array}{c}0.001 \\
(0.030)\end{array}$ & $\begin{array}{l}-0.022 \\
(0.018)\end{array}$ & $\begin{array}{l}0.030^{*} \\
(0.018)\end{array}$ & $\begin{array}{c}0.009 \\
(0.018)\end{array}$ & $\begin{array}{l}-0.008 \\
(0.016)\end{array}$ & $\begin{array}{l}0.046^{*} \\
(0.025)\end{array}$ & $\begin{array}{c}0.012 \\
(0.027)\end{array}$ & $\begin{array}{c}0.027 * * * \\
(0.008)\end{array}$ & $\begin{array}{c}0.039 * * * \\
(0.009)\end{array}$ \\
\hline Age squared & $\begin{array}{c}0.003 \\
(0.018)\end{array}$ & $\begin{array}{c}-0.046^{* *} \\
(0.019)\end{array}$ & $\begin{array}{c}0.041 \\
(0.057)\end{array}$ & $\begin{array}{l}-0.110^{*} \\
(0.064)\end{array}$ & $\begin{array}{l}-0.018 \\
(0.037)\end{array}$ & $\begin{array}{c}0.004 \\
(0.037)\end{array}$ & $\begin{array}{c}0.024 \\
(0.022)\end{array}$ & $\begin{array}{l}-0.036^{*} \\
(0.021)\end{array}$ & $\begin{array}{l}-0.015 \\
(0.023)\end{array}$ & $\begin{array}{c}0.007 \\
(0.019)\end{array}$ & $\begin{array}{l}-0.061^{*} \\
(0.031)\end{array}$ & $\begin{array}{l}-0.017 \\
(0.033)\end{array}$ & $\begin{array}{c}-0.036^{* * *} \\
(0.009)\end{array}$ & $\begin{array}{c}-0.043 * * * \\
(0.010)\end{array}$ \\
\hline Education: secondary & $\begin{array}{c}0.122 \\
(0.106)\end{array}$ & $\begin{array}{c}0.086 \\
(0.093)\end{array}$ & $\begin{array}{c}0.245 \\
(0.233)\end{array}$ & $\begin{array}{l}0.323 \\
(0.269)\end{array}$ & $\begin{array}{c}0.164 \\
(0.106)\end{array}$ & $\begin{array}{c}0.054 \\
(0.110)\end{array}$ & $\begin{array}{l}0.128^{*} \\
(0.072)\end{array}$ & $\begin{array}{l}0.076 \\
(0.071)\end{array}$ & $\begin{array}{l}-0.012 \\
(0.087)\end{array}$ & $\begin{array}{l}-0.049 \\
(0.068)\end{array}$ & $\begin{array}{l}-0.056 \\
(0.107)\end{array}$ & $\begin{array}{l}-0.032 \\
(0.109)\end{array}$ & $\begin{array}{c}0.239 * * * \\
(0.055)\end{array}$ & $\begin{array}{c}0.216^{* * *} \\
(0.050)\end{array}$ \\
\hline Education: University & $\begin{array}{c}0.369^{* * *} \\
(0.094)\end{array}$ & $\begin{array}{c}0.223 * * * \\
(0.078)\end{array}$ & $\begin{array}{c}0.280 \\
(0.226)\end{array}$ & $\begin{array}{c}0.182 \\
(0.268)\end{array}$ & $\begin{array}{c}0.111 \\
(0.119)\end{array}$ & $\begin{array}{c}0.110 \\
(0.126)\end{array}$ & $\begin{array}{c}0.295 * * * \\
(0.096)\end{array}$ & $\begin{array}{c}0.074 \\
(0.079)\end{array}$ & $\begin{array}{c}0.054 \\
(0.087)\end{array}$ & $\begin{array}{l}-0.117^{*} \\
(0.070)\end{array}$ & $\begin{array}{l}-0.026 \\
(0.115)\end{array}$ & $\begin{array}{c}0.056 \\
(0.114)\end{array}$ & $\begin{array}{c}0.454^{* * *} \\
(0.052)\end{array}$ & $\begin{array}{c}0.450 * * * \\
(0.046)\end{array}$ \\
\hline Married/cohabiting & $\begin{array}{l}-0.113^{*} \\
(0.058)\end{array}$ & $\begin{array}{c}-0.159 * * \\
(0.067)\end{array}$ & $\begin{array}{c}0.019 \\
(0.221)\end{array}$ & $\begin{array}{c}0.229 \\
(0.260)\end{array}$ & $\begin{array}{l}-0.113 \\
(0.106)\end{array}$ & $\begin{array}{c}0.026 \\
(0.121)\end{array}$ & $\begin{array}{l}-0.122 \\
(0.074)\end{array}$ & $\begin{array}{l}-0.001 \\
(0.078)\end{array}$ & $\begin{array}{c}0.039 \\
(0.073)\end{array}$ & $\begin{array}{l}-0.014 \\
(0.082)\end{array}$ & $\begin{array}{l}-0.110 \\
(0.126)\end{array}$ & $\begin{array}{l}-0.233 \\
(0.159)\end{array}$ & $\begin{array}{c}-0.120 * * * \\
(0.031)\end{array}$ & $\begin{array}{c}-0.191 * * * \\
(0.037)\end{array}$ \\
\hline Family size & $\begin{array}{c}0.036 \\
(0.031)\end{array}$ & $\begin{array}{c}0.017 \\
(0.033)\end{array}$ & $\begin{array}{l}-0.006 \\
(0.118)\end{array}$ & $\begin{array}{l}-0.139 \\
(0.134)\end{array}$ & $\begin{array}{c}0.005 \\
(0.062)\end{array}$ & $\begin{array}{l}-0.086 \\
(0.067)\end{array}$ & $\begin{array}{c}0.062 * * \\
(0.030)\end{array}$ & $\begin{array}{c}0.063^{* *} \\
(0.029)\end{array}$ & $\begin{array}{c}0.003 \\
(0.027)\end{array}$ & $\begin{array}{l}-0.012 \\
(0.024)\end{array}$ & $\begin{array}{c}-0.127^{* *} \\
(0.050)\end{array}$ & $\begin{array}{l}-0.029 \\
(0.057)\end{array}$ & $\begin{array}{c}-0.055^{* * *} \\
(0.019)\end{array}$ & $\begin{array}{l}-0.009 \\
(0.020)\end{array}$ \\
\hline Number of children & $\begin{array}{c}0.045 \\
(0.043)\end{array}$ & $\begin{array}{l}-0.004 \\
(0.044)\end{array}$ & $\begin{array}{l}-0.078 \\
(0.144)\end{array}$ & $\begin{array}{l}0.084 \\
(0.147)\end{array}$ & $\begin{array}{c}0.072 \\
(0.073)\end{array}$ & $\begin{array}{c}0.114 \\
(0.078)\end{array}$ & $\begin{array}{l}-0.057 \\
(0.037)\end{array}$ & $\begin{array}{l}-0.058^{*} \\
(0.034)\end{array}$ & $\begin{array}{l}-0.048 \\
(0.038)\end{array}$ & $\begin{array}{c}0.067 * * \\
(0.032)\end{array}$ & $\begin{array}{c}0.121^{* *} \\
(0.061)\end{array}$ & $\begin{array}{c}0.102 \\
(0.067)\end{array}$ & $\begin{array}{c}0.121^{* * *} \\
(0.023)\end{array}$ & $\begin{array}{l}0.048 * * \\
(0.024)\end{array}$ \\
\hline Weekly work hours & $\begin{array}{c}0.000 \\
(0.003)\end{array}$ & $\begin{array}{l}0.004 \\
(0.003)\end{array}$ & $\begin{array}{l}-0.002 \\
(0.013)\end{array}$ & $\begin{array}{l}-0.005 \\
(0.011)\end{array}$ & $\begin{array}{l}0.011 * * \\
(0.005)\end{array}$ & $\begin{array}{c}0.003 \\
(0.005)\end{array}$ & $\begin{array}{c}-0.004 * * * \\
(0.002)\end{array}$ & $\begin{array}{l}0.000 \\
(0.002)\end{array}$ & $\begin{array}{c}0.001 \\
(0.004)\end{array}$ & $\begin{array}{l}0.006^{*} \\
(0.003)\end{array}$ & $\begin{array}{l}0.000 \\
(0.003)\end{array}$ & $\begin{array}{l}-0.001 \\
(0.003)\end{array}$ & $\begin{array}{c}0.002 \\
(0.002)\end{array}$ & $\begin{array}{l}-0.001 \\
(0.001)\end{array}$ \\
\hline Part-time worker & $\begin{array}{c}-0.190^{*} \\
(0.097)\end{array}$ & $\begin{array}{c}0.153 \\
(0.164)\end{array}$ & $\begin{array}{l}-0.110 \\
(0.312)\end{array}$ & $\begin{array}{l}0.436 \\
(0.432)\end{array}$ & $\begin{array}{c}0.034 \\
(0.107)\end{array}$ & $\begin{array}{c}0.193 \\
(0.226)\end{array}$ & $\begin{array}{l}-0.100 \\
(0.073)\end{array}$ & $\begin{array}{l}0.072 \\
(0.095)\end{array}$ & $\begin{array}{c}0.126 \\
(0.090)\end{array}$ & $\begin{array}{c}0.418^{* * *} \\
(0.147)\end{array}$ & $\begin{array}{l}-0.030 \\
(0.092)\end{array}$ & $\begin{array}{l}-0.305^{*} \\
(0.183)\end{array}$ & $\begin{array}{l}-0.063 \\
(0.043)\end{array}$ & $\begin{array}{l}-0.054 \\
(0.060)\end{array}$ \\
\hline Weekday & $\begin{array}{c}0.238^{* * *} \\
(0.078)\end{array}$ & $\begin{array}{c}0.068 \\
(0.081)\end{array}$ & $\begin{array}{c}0.002 \\
(0.189)\end{array}$ & $\begin{array}{c}0.108 \\
(0.240)\end{array}$ & $\begin{array}{c}0.017 \\
(0.104)\end{array}$ & $\begin{array}{l}-0.083 \\
(0.124)\end{array}$ & $\begin{array}{c}0.087 \\
(0.055)\end{array}$ & $\begin{array}{c}0.066 \\
(0.047)\end{array}$ & $\begin{array}{c}0.081 \\
(0.074)\end{array}$ & $\begin{array}{c}0.015 \\
(0.067)\end{array}$ & $\begin{array}{c}0.284 * * * \\
(0.086)\end{array}$ & $\begin{array}{c}0.032 \\
(0.089)\end{array}$ & $\begin{array}{c}0.300^{* * * *} \\
(0.029)\end{array}$ & $\begin{array}{c}0.265^{* * *} \\
(0.029)\end{array}$ \\
\hline \multicolumn{15}{|l|}{ Transport mode } \\
\hline Rate: private vehicle & $\begin{array}{c}0.285 * * * \\
(0.079)\end{array}$ & $\begin{array}{l}0.442 * \\
(0.227)\end{array}$ & $\begin{array}{c}0.004 \\
(0.305)\end{array}$ & $\begin{array}{l}-0.286 \\
(0.229)\end{array}$ & $\begin{array}{l}-0.154 \\
(0.209)\end{array}$ & $\begin{array}{l}-0.261 \\
(0.213)\end{array}$ & $\begin{array}{c}-0.426^{* *} \\
(0.176)\end{array}$ & $\begin{array}{c}0.034 \\
(0.086)\end{array}$ & $\begin{array}{c}0.052 \\
(0.080)\end{array}$ & $\begin{array}{c}0.131 * * \\
(0.065)\end{array}$ & $\begin{array}{l}-0.072 \\
(0.157)\end{array}$ & $\begin{array}{c}0.060 \\
(0.195)\end{array}$ & $\begin{array}{c}-0.083 \\
(0.058)\end{array}$ & $\begin{array}{c}-0.170 * * \\
(0.077)\end{array}$ \\
\hline Rate: public transport & $\begin{array}{c}0.611^{* * *} \\
(0.136)\end{array}$ & $\begin{array}{c}0.924^{* * *} \\
(0.267)\end{array}$ & $\begin{array}{l}1.271^{* *} \\
(0.494)\end{array}$ & $\begin{array}{l}1.111 * * \\
(0.473)\end{array}$ & $\begin{array}{c}0.117 \\
(0.259)\end{array}$ & $\begin{array}{c}0.043 \\
(0.279)\end{array}$ & $\begin{array}{c}0.101 \\
(0.186)\end{array}$ & $\begin{array}{c}0.625^{* * *} \\
(0.139)\end{array}$ & $\begin{array}{c}0.650^{* * *} \\
(0.106)\end{array}$ & $\begin{array}{c}0.505^{* * *} \\
(0.117)\end{array}$ & $\begin{array}{c}0.586^{* * *} \\
(0.204)\end{array}$ & $\begin{array}{l}0.627^{*} \\
(0.359)\end{array}$ & $\begin{array}{c}0.722^{* * *} \\
(0.121)\end{array}$ & $\begin{array}{c}0.664 * * * \\
(0.127)\end{array}$ \\
\hline Rate: active & $\begin{array}{l}-0.012 \\
(0.026)\end{array}$ & $\begin{array}{c}0.143 \\
(0.245)\end{array}$ & $\begin{array}{c}0.156 \\
(0.321)\end{array}$ & $\begin{array}{l}-0.234 \\
(0.311)\end{array}$ & $\begin{array}{l}-0.173 \\
(0.229)\end{array}$ & $\begin{array}{l}-0.150 \\
(0.249)\end{array}$ & $\begin{array}{c}-0.370 * * \\
(0.175)\end{array}$ & $\begin{array}{c}0.150 \\
(0.097)\end{array}$ & $\begin{array}{c}-0.193 * * \\
(0.087)\end{array}$ & $\begin{array}{c}-0.181 * * \\
(0.084)\end{array}$ & $\begin{array}{l}-0.199 \\
(0.177)\end{array}$ & $\begin{array}{l}-0.318 \\
(0.210)\end{array}$ & $\begin{array}{c}-0.438 * * * \\
(0.093)\end{array}$ & $\begin{array}{c}-0.501 * * * \\
(0.098)\end{array}$ \\
\hline Constant & $\begin{array}{c}0.541 \\
(0.330)\end{array}$ & $\begin{array}{l}-0.335 \\
(0.408)\end{array}$ & $\begin{array}{c}1.540 \\
(1.118)\end{array}$ & $\begin{array}{l}-0.974 \\
(1.192)\end{array}$ & $\begin{array}{c}0.530 \\
(0.647)\end{array}$ & $\begin{array}{l}1.547^{* *} \\
(0.670)\end{array}$ & $\begin{array}{c}2.020 * * * \\
(0.400)\end{array}$ & $\begin{array}{c}0.412 \\
(0.395)\end{array}$ & $\begin{array}{c}0.958^{* *} \\
(0.405)\end{array}$ & $\begin{array}{c}1.166 * * * \\
(0.375)\end{array}$ & $\begin{array}{c}1.243^{* *} \\
(0.528)\end{array}$ & $\begin{array}{c}1.854 * * * \\
(0.589)\end{array}$ & $\begin{array}{c}0.777 * * * \\
(0.272)\end{array}$ & $\begin{array}{c}0.302 \\
(0.276)\end{array}$ \\
\hline Year F.E. & Yes & Yes & Yes & Yes & Yes & Yes & Yes & Yes & Yes & Yes & Yes & Yes & Yes & Yes \\
\hline Observations & 3,798 & 3,706 & 564 & 464 & 1,808 & 1,876 & 3,784 & 5,426 & 3,324 & 4,342 & 2,033 & 2,044 & 17,792 & 18,062 \\
\hline R-squared & 0.024 & 0.020 & 0.034 & 0.043 & 0.011 & 0.006 & 0.026 & 0.011 & 0.030 & 0.014 & 0.032 & 0.021 & 0.030 & 0.030 \\
\hline
\end{tabular}

Note: The sample (MTUS 2000-2018) has been restricted to countries with non-missing information on the main variables. The sample includes employed individuals who worked the diary day. The dependent variable is the log-of-minutes of difference between commuting to and from work. $*$ Significant at the $90 \%$ level; $* *$ significant at the $95 \%$ level; $* * *$ significant at the $99 \%$ level. 


\section{Appendix A. Additional tables}

Table A1. Sample composition

\begin{tabular}{lccc}
\hline Country & Years & N. Individuals & N. Episodes \\
\hline & & & \\
Canada & 2005,2010 & 9,912 & 20,883 \\
Finland & 2009,2010 & 1,331 & 2,614 \\
France & 2010 & 5,065 & 11,595 \\
Korea & 2009 & 13,577 & 27,750 \\
Spain & $2002,2003,2009,2010$ & 11,817 & 32,310 \\
UK & $2000,2001,2014,2015$ & 5,469 & 13,970 \\
US & $2003-2018$ & 43,346 & 93,957 \\
\hline
\end{tabular}

Note: The sample (MTUS 2000-2018) has been restricted to countries with non-missing information on the main variables. The sample includes employed individuals who worked the diary day. 
Table A2. Average commuting to and from work, including intermediate activities

\begin{tabular}{|c|c|c|c|c|c|c|}
\hline \multirow[b]{2}{*}{ Country } & \multirow[b]{2}{*}{ Sex } & \multicolumn{4}{|c|}{ Commuting time } & \multirow{2}{*}{$\begin{array}{c}\text { No. } \\
\text { Individuals }\end{array}$} \\
\hline & & Total & To work & From work & Difference & \\
\hline \multirow[t]{3}{*}{ Canada } & Women & 80.685 & 41.120 & 39.565 & $1.555^{*}$ & 4,913 \\
\hline & Men & 105.325 & 52.343 & 52.982 & -0.639 & 4,999 \\
\hline & Gender diff. & $-24.640 * * *$ & $-11.223 * * *$ & $-13.417 * * *$ & & \\
\hline \multirow[t]{3}{*}{ Finland } & Women & 59.535 & 32.644 & 26.891 & $5.753 * *$ & 722 \\
\hline & Men & 62.675 & 35.663 & 27.013 & $8.650 * * *$ & 609 \\
\hline & Gender diff. & $-3.140 *$ & -3.019 & -0.122 & & \\
\hline \multirow[t]{3}{*}{ France } & Women & 78.566 & 39.291 & 39.276 & 0.015 & 2,466 \\
\hline & Men & 91.318 & 46.698 & 44.620 & $2.078 *$ & 2,599 \\
\hline & Gender diff. & $-12.752 * * *$ & $-7.407 * * *$ & $-5.344 * * *$ & & \\
\hline \multirow[t]{3}{*}{ South Korea } & Women & 70.718 & 35.384 & 35.335 & 0.049 & 5,440 \\
\hline & Men & 75.162 & 37.905 & 37.257 & 0.648 & 8,137 \\
\hline & Gender diff. & $-4.444 * * *$ & $-2.521 * * *$ & $-1.922 * * *$ & & \\
\hline \multirow[t]{3}{*}{ Spain } & Women & 76.939 & 36.261 & 40.678 & $-4.417 * * *$ & 4,994 \\
\hline & Men & 99.540 & 45.893 & 53.647 & $-7.754 * * *$ & 6,823 \\
\hline & Gender diff. & $-22.601 * * *$ & $-9.632 * * *$ & $-12.969 * * *$ & & \\
\hline \multirow[t]{3}{*}{ UK } & Women & 58.219 & 34.556 & 23.662 & $10.894 * * *$ & 2,652 \\
\hline & Men & 84.630 & 48.144 & 36.486 & $11.658 * * *$ & 2,817 \\
\hline & Gender diff. & $-26.411 * * *$ & $-13.588 * * *$ & $-12.824 * * *$ & & \\
\hline \multirow[t]{3}{*}{ US } & Women & 59.230 & 32.864 & 26.366 & $6.498 * * *$ & 22,603 \\
\hline & Men & 80.529 & 42.020 & 38.509 & $3.511 * * *$ & 24,743 \\
\hline & Gender diff. & $-21.299 * * *$ & $-9.156 * * *$ & $-12.143 * * *$ & & \\
\hline
\end{tabular}

Note: Standard deviations available upon request. The sample (MTUS 2000-2018) has been restricted to countries with non-missing information on the main variables. The sample includes employed individuals who worked the diary day. Commuting time is measured in minutes, including ancillary activities done within commuting trips. Differences in commuting time to/from work are computed as the time of commuting to work, minus the time of commuting from work. Differences between women and men are computed as the average time of women, minus the average time of men. * Significant at the $90 \%$ level; ** significant at the $95 \%$ level; $* * *$ significant at the $99 \%$ level; all computed according to $t$-type tests. 
Table A3. Additional descriptives

\begin{tabular}{lcccc}
\hline \multirow{2}{*}{ Variables } & \multicolumn{2}{c}{ Women } & \multicolumn{2}{c}{ Men } \\
\cline { 2 - 5 } & Mean & S. Dev. & Mean & S. Dev \\
Commuter & 0.998 & 0.042 & 0.998 & 0.040 \\
Commuting time & 47.908 & 40.471 & 58.540 & 49.889 \\
Commuting to work & 26.437 & 22.659 & 30.399 & 28.084 \\
Commuting from work & 21.472 & 24.036 & 28.141 & 30.081 \\
Age & 41.600 & 11.370 & 41.707 & 11.054 \\
Education: basic & 0.100 & 0.300 & 0.119 & 0.324 \\
Education: secondary & 0.311 & 0.463 & 0.351 & 0.477 \\
Education: University & 0.588 & 0.492 & 0.530 & 0.499 \\
Married/cohabiting & 0.661 & 0.473 & 0.767 & 0.423 \\
Family size & 2.923 & 1.362 & 3.110 & 1.418 \\
Presence of children & 0.488 & 0.500 & 0.503 & 0.500 \\
Number of children & 0.835 & 1.026 & 0.911 & 1.094 \\
Weekly work hours & 39.389 & 12.192 & 45.678 & 12.114 \\
Paid work time & 458.741 & 136.278 & 509.427 & 139.988 \\
Part-time worker & 0.194 & 0.395 & 0.052 & 0.223 \\
& \multicolumn{4}{c}{50,727} \\
No. Individuals & \multicolumn{4}{c}{43,790} \\
\hline
\end{tabular}

Note: The sample (MTUS 2000-2018) has been restricted to countries with nonmissing information on the main variables. The sample includes employed individuals who worked the diary day. Commuting times are measured in minutes. Paid work time is measured in minutes per day. 
Table A4. Additional descriptives, by country

\begin{tabular}{|c|c|c|c|c|c|c|c|c|c|c|c|c|c|c|}
\hline \multirow[b]{2}{*}{ VARIABLES } & \multicolumn{2}{|c|}{ CANADA } & \multicolumn{2}{|c|}{ FINLAND } & \multicolumn{2}{|c|}{ FRANCE } & \multicolumn{2}{|c|}{ KOREA } & \multicolumn{2}{|c|}{ SPAIN } & \multicolumn{2}{|c|}{ UK } & \multicolumn{2}{|c|}{ US } \\
\hline & Women & Men & Women & Men & Women & Men & Women & Men & Women & Men & Women & Men & Women & Men \\
\hline Age & 40.119 & 40.284 & 43.402 & 43.449 & 42.420 & 41.772 & 40.466 & 42.108 & 38.117 & 39.806 & 40.192 & 41.018 & 42.706 & 42.363 \\
\hline Education: basic & 0.074 & 0.109 & 0.099 & 0.149 & 0.164 & 0.155 & 0.218 & 0.131 & 0.125 & 0.173 & 0.160 & 0.196 & 0.060 & 0.085 \\
\hline Education: sec. & 0.156 & 0.173 & 0.345 & 0.422 & 0.535 & 0.593 & 0.593 & 0.584 & 0.391 & 0.448 & 0.364 & 0.369 & 0.238 & 0.260 \\
\hline Education: Univ. & 0.770 & 0.718 & 0.555 & 0.429 & 0.301 & 0.252 & 0.189 & 0.285 & 0.484 & 0.379 & 0.476 & 0.435 & 0.701 & 0.655 \\
\hline Married/cohabiting & 0.564 & 0.666 & 0.861 & 0.868 & 0.730 & 0.782 & 0.829 & 0.875 & 0.809 & 0.883 & 0.871 & 0.930 & 0.580 & 0.701 \\
\hline Family size & 2.548 & 2.742 & 2.883 & 2.951 & 2.715 & 2.869 & 3.325 & 3.357 & 3.392 & 3.520 & 3.073 & 3.203 & 2.825 & 3.013 \\
\hline Presence of children & 0.343 & 0.383 & 0.418 & 0.482 & 0.452 & 0.471 & 0.460 & 0.522 & 0.465 & 0.477 & 0.467 & 0.510 & 0.531 & 0.528 \\
\hline Number of children & 0.519 & 0.618 & 0.779 & 0.883 & 0.755 & 0.851 & 0.780 & 0.905 & 0.711 & 0.757 & 0.794 & 0.909 & 0.938 & 1.013 \\
\hline Weekly work hours & 39.473 & 45.706 & 36.270 & 40.629 & 32.685 & 37.970 & 48.561 & 53.254 & 36.211 & 41.039 & 32.859 & 44.156 & 39.626 & 45.718 \\
\hline Part-time worker & 0.103 & 0.032 & 0.103 & 0.025 & 0.245 & 0.044 & 0.174 & 0.066 & 0.197 & 0.029 & 0.384 & 0.047 & 0.190 & 0.060 \\
\hline No. Episodes & 4,913 & 4,999 & 722 & 609 & 2,466 & 25,99 & 5,440 & 8,137 & 4,994 & 6,823 & 2,652 & 2,817 & 22,603 & 24,743 \\
\hline
\end{tabular}

Note: Standard deviations available upon request. The sample (MTUS 2000-2018) has been restricted to the countries with non-missing information on the main variables.

The sample includes employed individuals who worked the diary day. Commuting times are measured in minutes. Paid work time is measured in minutes per day. 
Table A5. Averages of commuting episode variables, by country

\begin{tabular}{|c|c|c|c|c|c|c|c|c|c|}
\hline \multirow[b]{2}{*}{ VARIABLES } & \multicolumn{3}{|c|}{ CANADA } & \multicolumn{3}{|c|}{ FINLAND } & \multicolumn{3}{|c|}{ FRANCE } \\
\hline & To work & $\begin{array}{l}\text { From } \\
\text { work }\end{array}$ & Diff. & To work & $\begin{array}{l}\text { From } \\
\text { work }\end{array}$ & Diff. & To work & $\begin{array}{l}\text { From } \\
\text { work }\end{array}$ & Diff. \\
\hline \multicolumn{10}{|l|}{ A. Women } \\
\hline Episode duration & 21.964 & 23.318 & $\begin{array}{c}- \\
1.354 * * *\end{array}$ & 25.022 & 24.067 & 0.955 & 27.128 & 27.596 & -0.468 \\
\hline Episode: private vehicle & 0.813 & 0.815 & -0.002 & 0.622 & 0.616 & 0.006 & 0.748 & 0.734 & 0.014 \\
\hline Episode: public transport & 0.083 & 0.087 & -0.004 & 0.042 & 0.043 & -0.001 & 0.071 & 0.080 & -0.009 \\
\hline Episode: active & 0.101 & 0.096 & 0.005 & 0.282 & 0.301 & -0.019 & 0.147 & 0.147 & 0.000 \\
\hline Episode: other mode & 0.006 & 0.006 & 0.000 & 0.157 & 0.144 & 0.013 & 0.052 & 0.058 & -0.006 \\
\hline With whom: alone & 0.851 & 0.827 & $0.024 * * *$ & 0.735 & 0.751 & -0.016 & 0.870 & 0.873 & -0.003 \\
\hline With whom: child & 0.023 & 0.038 & $\begin{array}{c}- \\
0.015^{* * *}\end{array}$ & 0.004 & 0.010 & -0.006 & 0.057 & 0.042 & $0.015^{* *}$ \\
\hline With whom: partner & 0.060 & 0.065 & -0.005 & 0.115 & 0.067 & $0.048^{* * *}$ & 0.041 & 0.038 & 0.003 \\
\hline Episodes per trip & 1.385 & 1.225 & $0.160 * * *$ & 1.070 & 1.023 & $0.047 * * *$ & 1.414 & 1.355 & $0.059 * * *$ \\
\hline No. Episodes & 5,806 & 4,678 & & 737 & 685 & & 3,007 & 2,759 & \\
\hline \multicolumn{10}{|l|}{ B. Men } \\
\hline Episode duration & 25.251 & 26.788 & $\begin{array}{c}- \\
1.537 * * *\end{array}$ & 26.238 & 25.685 & 0.553 & 30.589 & 31.078 & -0.489 \\
\hline Episode: private vehicle & 0.840 & 0.844 & -0.004 & 0.696 & 0.707 & -0.011 & 0.780 & 0.772 & 0.008 \\
\hline Episode: public transport & 0.061 & 0.059 & 0.002 & 0.012 & 0.022 & -0.010 & 0.064 & 0.075 & -0.011 \\
\hline Episode: active & 0.093 & 0.091 & 0.002 & 0.170 & 0.167 & 0.003 & 0.109 & 0.101 & 0.008 \\
\hline Episode: other mode & 0.022 & 0.022 & 0.000 & 0.183 & 0.163 & 0.020 & 0.077 & 0.083 & -0.006 \\
\hline With whom: alone & 0.870 & 0.866 & 0.004 & 0.821 & 0.819 & 0.002 & 0.897 & 0.897 & 0.000 \\
\hline With whom: child & 0.009 & 0.013 & $-0.004 * *$ & 0.006 & 0.003 & 0.003 & 0.025 & 0.017 & $0.008^{* *}$ \\
\hline With whom: partner & 0.038 & 0.035 & 0.003 & 0.055 & 0.041 & 0.014 & 0.031 & 0.025 & 0.006 \\
\hline Episodes per trip & 1.390 & 1.291 & $0.099 * * *$ & 1.100 & 1.063 & 0.037 & 1.421 & 1.355 & $0.066 * * *$ \\
\hline No. Episodes & 5,907 & 5,254 & & 610 & 585 & & 3,121 & 2,881 & \\
\hline
\end{tabular}

Note: Standard deviations available upon request. The sample (MTUS 2000-2018) has been restricted to countries with non-missing information on the main variables. The sample includes commuting episodes of employed individuals who worked the diary day. Episode duration is measured in minutes. Start time is measured in hours. Private vehicle includes car, truck, or motorcycle. Active commuting includes walking and physical modes of transport. Other trips are classified as "unspecified". Differences in commuting time to/from work are computed as the time of commuting to work, minus the time of commuting from work. * Significant at the $90 \%$ level; ** significant at the $95 \%$ level; $* * *$ significant at the $99 \%$ level; all computed according to $t$-type tests. 
Table A5 (Cont.). Averages of commuting episode variables, by country

\begin{tabular}{|c|c|c|c|c|c|c|c|c|c|c|c|c|}
\hline \multirow[b]{2}{*}{ VARIABLES } & \multicolumn{3}{|c|}{ KOREA } & \multicolumn{3}{|c|}{ SPAIN } & \multicolumn{3}{|c|}{ UK } & \multicolumn{3}{|c|}{ US } \\
\hline & To work & $\begin{array}{l}\text { From } \\
\text { work }\end{array}$ & Diff. & To work & $\begin{array}{l}\text { From } \\
\text { work }\end{array}$ & Diff. & To work & $\begin{array}{l}\text { From } \\
\text { work }\end{array}$ & Diff. & To work & $\begin{array}{l}\text { From } \\
\text { work }\end{array}$ & Diff. \\
\hline \multicolumn{13}{|l|}{ A. Women } \\
\hline Episode duration & 31.893 & 31.376 & 0.517 & 21.060 & 21.925 & $\stackrel{-}{0.865^{* * *}}$ & 19.218 & 20.921 & $\begin{array}{c}- \\
1.703^{* * *}\end{array}$ & 19.515 & 21.945 & $2.430^{-} * * *$ \\
\hline Episode: private vehicle & 0.380 & 0.399 & $-0.019 * *$ & 0.365 & 0.360 & 0.005 & 0.595 & 0.597 & -0.002 & 0.852 & 0.848 & 0.004 \\
\hline Episode: public transport & 0.173 & 0.168 & 0.005 & 0.150 & 0.136 & $0.014^{* *}$ & 0.134 & 0.124 & 0.010 & 0.037 & 0.049 & $\begin{array}{c}- \\
0.012^{* * *}\end{array}$ \\
\hline Episode: active & 0.430 & 0.415 & $0.015^{*}$ & 0.255 & 0.242 & $0.013 *$ & 0.207 & 0.206 & 0.001 & 0.062 & 0.058 & 0.004 \\
\hline Episode: other mode & 0.017 & 0.018 & -0.001 & 0.232 & 0.263 & $\stackrel{-}{-} 0.031^{* * *}$ & 0.079 & 0.092 & $-0.013 *$ & 0.051 & 0.047 & $0.004 * *$ \\
\hline With whom: alone & 0.866 & 0.787 & $0.079 * * *$ & 0.770 & 0.714 & $0.056 * * *$ & 0.637 & 0.636 & 0.001 & 0.873 & 0.880 & $\begin{array}{c}- \\
0.007 * * *\end{array}$ \\
\hline With whom: child & 0.002 & 0.002 & 0.000 & 0.017 & 0.020 & -0.003 & 0.042 & 0.030 & $0.012 * *$ & 0.031 & 0.033 & -0.002 \\
\hline With whom: partner & 0.063 & 0.074 & $-0.011^{* *}$ & 0.045 & 0.051 & $-0.006^{*}$ & 0.087 & 0.090 & -0.003 & 0.033 & 0.031 & 0.002 \\
\hline Episodes per trip & 1.110 & 1.106 & 0.004 & 1.724 & 1.691 & $0.033 * * *$ & 2.050 & 1.513 & $0.537 * * *$ & 1.537 & 1.108 & $0.429 * * *$ \\
\hline No. Episodes & 5,774 & 5,766 & & 6,906 & 6,685 & & 3,959 & 2,636 & & 26,758 & 17,025 & \\
\hline \multicolumn{13}{|l|}{ B. Men } \\
\hline Episode duration & 35.904 & 35.130 & $0.774 * *$ & 22.428 & 23.757 & $\overline{-}^{-}$ & 24.872 & 26.617 & $\begin{array}{c}- \\
1.745^{* * *}\end{array}$ & 22.561 & 26.169 & $\begin{array}{c}- \\
3.608^{* * *}\end{array}$ \\
\hline Episode: private vehicle & 0.662 & 0.681 & $-0.019 * *$ & 0.503 & 0.478 & $0.025^{* * *}$ & 0.651 & 0.647 & 0.004 & 0.852 & 0.864 & $\begin{array}{c}- \\
0.012 * * *\end{array}$ \\
\hline Episode: public transport & 0.066 & 0.066 & 0.000 & 0.072 & 0.065 & $0.007 *$ & 0.115 & 0.121 & -0.006 & 0.034 & 0.040 & $\begin{array}{c}- \\
0.006^{* * *}\end{array}$ \\
\hline Episode: active & 0.223 & 0.200 & $0.023 * * *$ & 0.137 & 0.133 & 0.004 & 0.167 & 0.165 & 0.002 & 0.068 & 0.058 & $0.010^{* * *}$ \\
\hline Episode: other mode & 0.050 & 0.054 & -0.004 & 0.294 & 0.330 & $\begin{array}{c}- \\
0.036^{* * *}\end{array}$ & 0.108 & 0.111 & -0.003 & 0.052 & 0.047 & $0.005^{* * *}$ \\
\hline With whom: alone & 0.898 & 0.841 & $0.057 * * *$ & 0.785 & 0.746 & $0.039^{* * *}$ & 0.681 & 0.686 & -0.005 & 0.882 & 0.905 & $0.023^{-} * * *$ \\
\hline With whom: child & 0.000 & 0.000 & 0.000 & 0.006 & 0.013 & $\begin{array}{c}- \\
0.007^{* * *}\end{array}$ & 0.022 & 0.016 & $0.006^{*}$ & 0.010 & 0.012 & -0.002 \\
\hline With whom: partner & 0.036 & 0.040 & -0.004 & 0.024 & 0.031 & $0.007 * * *$ & 0.076 & 0.071 & 0.005 & 0.022 & 0.020 & $0.002 *$ \\
\hline Episodes per trip & 1.048 & 1.067 & $\begin{array}{c}- \\
0.019 * * *\end{array}$ & 1.692 & 1.694 & $-0.002 *$ & 2.057 & 1.742 & $0.315 * * *$ & 1.532 & 1.212 & $0.320^{* * *}$ \\
\hline No. Episodes & 8,131 & 8,334 & & 9,493 & 9,515 & & 4,148 & 3,223 & & 29,163 & 22,057 & \\
\hline
\end{tabular}

Note: Standard deviations available upon request. The sample (MTUS 2000-2018) has been restricted to countries with non-missing information on the main variables. The sample includes commuting episodes of employed individuals who worked the diary day. Episode duration is measured in minutes. Start time is measured in hours. Private vehicle includes car, truck, or motorcycle. Active commuting includes walking and physical ways of transport. Other trips are classified as "unspecified". Differences in commuting time to/from work are computed as the time of commuting to work, minus the time of commuting from work. * Significant at the $90 \%$ level; ** significant at the $95 \%$ level; $* * *$ significant at the $99 \%$ level; all computed according to $t$-type tests. 
Table A6. Details on the timing of commuting

\begin{tabular}{|c|c|c|c|c|c|c|c|c|c|c|c|c|}
\hline \multirow[b]{3}{*}{$\begin{array}{l}\text { Hour of } \\
\text { the day }\end{array}$} & \multicolumn{4}{|c|}{ CANADA } & \multicolumn{4}{|c|}{ FINLAND } & \multicolumn{4}{|c|}{ FRANCE } \\
\hline & \multicolumn{2}{|c|}{ Women } & \multicolumn{2}{|c|}{ Men } & \multicolumn{2}{|c|}{ Women } & \multicolumn{2}{|c|}{ Men } & \multicolumn{2}{|c|}{ Women } & \multicolumn{2}{|c|}{ Men } \\
\hline & $\begin{array}{c}\text { To } \\
\text { work }\end{array}$ & $\begin{array}{l}\text { From } \\
\text { work }\end{array}$ & $\begin{array}{c}\text { To } \\
\text { work }\end{array}$ & $\begin{array}{l}\text { From } \\
\text { work }\end{array}$ & $\begin{array}{c}\text { To } \\
\text { work }\end{array}$ & $\begin{array}{l}\text { From } \\
\text { work }\end{array}$ & $\begin{array}{c}\text { To } \\
\text { work }\end{array}$ & $\begin{array}{l}\text { From } \\
\text { work }\end{array}$ & $\begin{array}{c}\text { To } \\
\text { work }\end{array}$ & $\begin{array}{l}\text { From } \\
\text { work }\end{array}$ & $\begin{array}{c}\text { To } \\
\text { work }\end{array}$ & $\begin{array}{l}\text { From } \\
\text { work }\end{array}$ \\
\hline $4 \mathrm{am}$ & 0.010 & 0.001 & 0.035 & 0.004 & 0.006 & 0.000 & 0.010 & 0.003 & 0.010 & 0.001 & 0.031 & 0.003 \\
\hline $5 \mathrm{am}$ & 0.045 & 0.003 & 0.092 & 0.009 & 0.058 & 0.002 & 0.096 & 0.009 & 0.025 & 0.003 & 0.057 & 0.011 \\
\hline 6am & 0.149 & 0.006 & 0.240 & 0.018 & 0.170 & 0.003 & 0.264 & 0.007 & 0.074 & 0.006 & 0.126 & 0.007 \\
\hline $7 \mathrm{am}$ & 0.331 & 0.022 & 0.323 & 0.028 & 0.339 & 0.013 & 0.259 & 0.003 & 0.305 & 0.013 & 0.382 & 0.011 \\
\hline $8 \mathrm{am}$ & 0.302 & 0.020 & 0.195 & 0.020 & 0.209 & 0.009 & 0.137 & 0.002 & 0.345 & 0.012 & 0.269 & 0.007 \\
\hline $9 \mathrm{am}$ & 0.074 & 0.009 & 0.055 & 0.0 & 0.0 & 0.008 & 0.056 & & 0.088 & 0.012 & 0.076 & 0.008 \\
\hline 10am & 038 & 0.007 & 0.02 & 0.0 & 0.025 & 0.004 & 0.019 & 0.0 & 0.022 & 0.015 & 0.024 & 0.010 \\
\hline & 032 & 0.018 & 0.02 & 0.0 & 0.0 & 0.009 & 0.007 & & 0.020 & 0.036 & 0.025 & 0.042 \\
\hline Noon & 0.058 & 0.042 & 0.057 & 0.055 & 0.029 & 0.016 & 0.010 & 0.010 & 0.046 & 0.165 & 0.051 & 0.161 \\
\hline $1 \mathrm{pm}$ & 0.040 & 0.030 & 0.042 & 0.025 & 0.0 & 0.041 & 0.020 & 0.020 & 0.148 & 0.043 & 0.152 & 0.050 \\
\hline $2 \mathrm{pm}$ & 0.029 & 0.035 & 0.034 & 0.034 & 0.013 & 0.100 & 0.011 & 0.101 & 0.037 & 0.041 & 0.026 & 0.040 \\
\hline $3 \mathrm{pm}$ & 0.031 & 0.090 & 0.027 & 0.087 & 0.018 & 0.209 & 0.010 & 0.199 & 0.015 & 0.040 & 0.014 & 0.044 \\
\hline $4 \mathrm{pm}$ & 0.025 & 0.201 & 0.026 & 0.199 & 0.013 & 0.229 & 0.003 & 0.208 & 0.022 & 0.112 & 0.012 & 0.110 \\
\hline $5 \mathrm{pm}$ & 024 & 0.228 & & & & 0.124 & & & 0.014 & 0.212 & 0.013 & 0.225 \\
\hline $6 \mathrm{pm}$ & 0.015 & 0.088 & 0.020 & 0.12 & & 0.055 & 0.004 & & 0.012 & 0.179 & 0.009 & 0.214 \\
\hline $7 \mathrm{pm}$ & 0.010 & 0.044 & 0.011 & 0.056 & 0.009 & 0.021 & 0.003 & 0.0 & 0.008 & 0.112 & 0.009 & 0.121 \\
\hline $8 \mathrm{pm}$ & 0.005 & 0.034 & 0.007 & 0.034 & 0.012 & 0.025 & 0.002 & 0.023 & 0.008 & 0.053 & 0.015 & 0.048 \\
\hline $9 \mathrm{pm}$ & 0.005 & 0.030 & 0.008 & 0.031 & 0.006 & 0.046 & 0.009 & 0.025 & 0.003 & 0.023 & 0.009 & 0.035 \\
\hline $10 \mathrm{pm}$ & 0.006 & 0.020 & 0.011 & 0.025 & 0.001 & 0.027 & 0.004 & 0.019 & 0.002 & 0.010 & 0.003 & 0.017 \\
\hline $11 \mathrm{pm}$ & 0.004 & 0.017 & 0.004 & 0.022 & 0.000 & 0.010 & 0.000 & 0.014 & 0.001 & 0.004 & 0.001 & 0.008 \\
\hline Midnight & 0.002 & 0.015 & 0.002 & & 0.000 & 0.004 & 0.002 & & 0.001 & 0.001 & 0.002 & 0.003 \\
\hline $1 \mathrm{am}$ & & & & & & & & & & 0.002 & & 0.002 \\
\hline $2 \mathrm{am}$ & 0.002 & 0.004 & 0.002 & & & 0.000 & 0.002 & & 0.000 & 0.000 & 0.002 & 0.002 \\
\hline $3 \mathrm{am}$ & 0.002 & 0.003 & 0.006 & 0.005 & 0.001 & 0.001 & 0.001 & 0.000 & 0.002 & 0.001 & 0.008 & 0.001 \\
\hline
\end{tabular}

The sample includes employed individuals who worked the diantries 
Table A6 (Cont.). Details on the timing of commuting

\begin{tabular}{|c|c|c|c|c|c|c|c|c|c|c|c|c|c|c|c|c|}
\hline \multirow[b]{3}{*}{$\begin{array}{l}\text { Hour of } \\
\text { the day }\end{array}$} & \multicolumn{4}{|c|}{ KOREA } & \multicolumn{4}{|c|}{ SPAIN } & \multicolumn{4}{|c|}{ UK } & \multicolumn{4}{|c|}{ US } \\
\hline & \multicolumn{2}{|c|}{ Women } & \multicolumn{2}{|c|}{ Men } & \multicolumn{2}{|c|}{ Women } & \multicolumn{2}{|c|}{ Men } & \multicolumn{2}{|c|}{ Women } & \multicolumn{2}{|c|}{ Men } & \multicolumn{2}{|c|}{ Women } & \multicolumn{2}{|c|}{ Men } \\
\hline & $\begin{array}{c}\text { To } \\
\text { work }\end{array}$ & $\begin{array}{l}\text { From } \\
\text { work }\end{array}$ & $\begin{array}{c}\text { To } \\
\text { work }\end{array}$ & $\begin{array}{l}\text { From } \\
\text { work }\end{array}$ & $\begin{array}{c}\text { To } \\
\text { work }\end{array}$ & $\begin{array}{l}\text { From } \\
\text { work }\end{array}$ & $\begin{array}{c}\text { To } \\
\text { work }\end{array}$ & $\begin{array}{l}\text { From } \\
\text { work }\end{array}$ & $\begin{array}{c}\text { To } \\
\text { work }\end{array}$ & $\begin{array}{l}\text { From } \\
\text { work }\end{array}$ & $\begin{array}{c}\text { To } \\
\text { work }\end{array}$ & $\begin{array}{l}\text { From } \\
\text { work }\end{array}$ & $\begin{array}{c}\text { To } \\
\text { work }\end{array}$ & $\begin{array}{l}\text { From } \\
\text { work }\end{array}$ & $\begin{array}{c}\text { To } \\
\text { work }\end{array}$ & $\begin{array}{l}\text { From } \\
\text { work }\end{array}$ \\
\hline 4am & 0.004 & 0.004 & 0.012 & 0.004 & 0.002 & 0.001 & 0.007 & 0.002 & 0.007 & 0.000 & 0.015 & 0.001 & 0.015 & 0.001 & 0.039 & 0.002 \\
\hline $5 \mathrm{am}$ & 0.023 & 0.008 & 0.047 & 0.009 & 0.018 & 0.003 & 0.045 & 0.006 & 0.017 & 0.001 & 0.079 & 0.006 & 0.053 & 0.002 & 0.107 & 0.005 \\
\hline 6am & 0.066 & 0.005 & 0.164 & 0.016 & 0.070 & 0.006 & 0.128 & 0.017 & 0.078 & 0.002 & 0.170 & 0.015 & 0.153 & 0.006 & 0.217 & 0.011 \\
\hline $7 \mathrm{am}$ & 0.235 & 0.007 & 0.382 & 0.019 & 0.265 & 0.004 & 0.394 & 0.011 & 0.266 & 0.007 & 0.341 & 0.009 & 0.305 & 0.015 & 0.257 & 0.015 \\
\hline $8 \mathrm{am}$ & 0.410 & 0.008 & 0.379 & 0.021 & 0.299 & 0.011 & 0.225 & 0.009 & 0.409 & 0.014 & 0.289 & 0.008 & 0.208 & 0.008 & 0.150 & 0.010 \\
\hline 9am & 0.200 & 0.008 & 0.112 & 0.013 & 0.158 & 0.009 & 0.071 & 0.005 & 0.129 & 0.011 & 0.090 & 0.006 & 0.075 & 0.006 & 0.059 & 0.008 \\
\hline $10 \mathrm{am}$ & 0.078 & 0.006 & 0.033 & 0.009 & 0.031 & 0.010 & 0.020 & 0.006 & 0.030 & 0.003 & 0.027 & 0.007 & 0.037 & 0.007 & 0.030 & 0.009 \\
\hline $11 \mathrm{am}$ & 0.037 & 0.009 & 0.014 & 0.007 & 0.018 & 0.017 & 0.010 & 0.007 & 0.033 & 0.011 & 0.017 & 0.012 & 0.032 & 0.013 & 0.029 & 0.014 \\
\hline Noon & 0.027 & 0.015 & 0.013 & 0.013 & 0.022 & 0.036 & 0.012 & 0.033 & 0.032 & 0.040 & 0.023 & 0.025 & 0.059 & 0.026 & 0.070 & 0.029 \\
\hline $1 \mathrm{pm}$ & 0.031 & 0.017 & 0.016 & 0.012 & 0.042 & 0.163 & 0.051 & 0.198 & 0.038 & 0.042 & 0.036 & 0.024 & 0.056 & 0.024 & 0.059 & 0.022 \\
\hline $2 \mathrm{pm}$ & 0.021 & 0.033 & 0.018 & 0.015 & 0.086 & 0.222 & 0.134 & 0.222 & 0.023 & 0.039 & 0.024 & 0.033 & 0.035 & 0.040 & 0.037 & 0.042 \\
\hline $3 \mathrm{pm}$ & 0.018 & 0.046 & 0.013 & 0.028 & 0.122 & 0.191 & 0.122 & 0.147 & 0.019 & 0.059 & 0.012 & 0.053 & 0.028 & 0.075 & 0.026 & 0.095 \\
\hline $4 \mathrm{pm}$ & 0.016 & 0.078 & 0.010 & 0.042 & 0.102 & 0.069 & 0.065 & 0.045 & 0.023 & 0.122 & 0.016 & 0.150 & 0.021 & 0.115 & 0.020 & 0.145 \\
\hline $5 \mathrm{pm}$ & 0.019 & 0.177 & 0.014 & 0.160 & 0.033 & 0.061 & 0.024 & 0.063 & 0.017 & 0.204 & 0.025 & 0.263 & 0.017 & 0.144 & 0.019 & 0.184 \\
\hline $6 \mathrm{pm}$ & 0.015 & 0.276 & 0.014 & 0.329 & 0.017 & 0.072 & 0.012 & 0.140 & 0.013 & 0.095 & 0.021 & 0.185 & 0.011 & 0.072 & 0.013 & 0.109 \\
\hline $7 \mathrm{pm}$ & 0.012 & 0.166 & 0.014 & 0.220 & 0.010 & 0.089 & 0.014 & 0.174 & 0.008 & 0.040 & 0.012 & 0.072 & 0.005 & 0.038 & 0.008 & 0.051 \\
\hline $8 \mathrm{pm}$ & 0.008 & 0.100 & 0.009 & 0.119 & 0.010 & 0.121 & 0.012 & 0.138 & 0.007 & 0.026 & 0.009 & 0.034 & 0.004 & 0.024 & 0.006 & 0.026 \\
\hline $9 \mathrm{pm}$ & 0.006 & 0.098 & & 0.088 & 0.013 & 0.066 & 0.025 & & 0.011 & 0.022 & 0.013 & & 0.005 & 0.020 & 0.007 & 0.024 \\
\hline $10 \mathrm{pm}$ & 0.003 & 0.078 & 0.005 & 0.068 & 0.002 & 0.065 & 0.006 & 0.053 & 0.003 & 0.021 & 0.006 & 0.018 & 0.007 & 0.017 & 0.007 & 0.021 \\
\hline $11 \mathrm{pm}$ & 0.001 & 0.037 & 0.003 & 0.041 & 0.002 & 0.022 & 0.003 & 0.022 & 0.001 & 0.011 & 0.002 & 0.014 & 0.003 & 0.015 & 0.003 & 0.019 \\
\hline Midnight & 0.001 & 0.013 & 0.002 & 0.013 & 0.000 & 0.014 & 0.001 & 0.014 & 0.000 & 0.006 & 0.001 & 0.012 & 0.001 & 0.007 & 0.001 & 0.011 \\
\hline $1 \mathrm{am}$ & 0.001 & 0.008 & 0.001 & 0.008 & 0.000 & 0.006 & 0.001 & 0.007 & 0.001 & 0.003 & 0.000 & 0.005 & 0.001 & 0.003 & 0.002 & 0.006 \\
\hline $2 \mathrm{am}$ & 0.001 & 0.010 & 0.002 & 0.006 & 0.001 & 0.004 & 0.001 & 0.004 & 0.001 & 0.002 & 0.000 & 0.003 & 0.002 & 0.002 & 0.004 & 0.005 \\
\hline $3 \mathrm{am}$ & 0.000 & 0.000 & 0.000 & 0.000 & 0.000 & 0.003 & 0.001 & 0.003 & 0.000 & 0.001 & 0.003 & 0.005 & 0.003 & 0.001 & 0.007 & 0.004 \\
\hline
\end{tabular}

individuals who worked the diary day. 